\title{
Aldehydes as Wort Off-Flavours in Alcohol-Free Beers-Origin and Control
}

\author{
D. C. Gernat ${ }^{1}$ (D) $\cdot$ E. Brouwer ${ }^{2} \cdot$ M. Ottens ${ }^{1}$
}

Received: 12 July 2019 / Accepted: 31 October 2019 / Published online: 3 December 2019

(C) The Author(s) 2019

\begin{abstract}
Although present in concentrations in microgrammes per litre level, aldehydes, in particular those derived from Strecker degradation, are known to majorly contribute to the undesired wort flavour of alcohol-free beers. In order to improve currently available products, one needs to understand the underlying cause for the over-prevalence and identify leverage points and methods to selectively reduce the aldehydes in alcohol-free beers. This work gives a short overview on relevant flavour-active wort flavours identified in alcohol-free beer and on their involved chemical formation pathways. Consequently, aldehyde removal technologies in general and in brewing industry are presented. Adsorptive removal of off-flavours by aldehydescavenging groups is already widely exploited in the packaging industry and may achieve reduction of these components to near depletion, depending on the process conditions. Its principles are adaptable to recovering off-flavours before filling. Also, supercritical $\mathrm{CO}_{2}$ extraction has been successfully applied to separate flavours from food matrices. In brewing, the focus has been set to biologic conversion by restricted fermentation steps, but the reduction of key components of more than $70 \%$ is not achieved. Newer developments focus on thermal separation techniques that not only include non-specific physical dealcoholisation but also more selective technologies such as pervaporation, where aldehydes are reduced to near depletion. However, for most unit operations, selectivity and capacity are not yet investigated. Future research should explore the shortcomings of current techniques and overcome bottlenecks either by developing more specific methods for aldehyde removal and/ or a clever combination of unit operations to optimise the separation and process integration.
\end{abstract}

Keywords Strecker aldehydes $\cdot$ Alcohol-free beer $\cdot$ Removal $\cdot$ Wort flavour

\section{Introduction}

Current market trends show that consumers are shifting more and more to a health-conscious lifestyle (Lehnert et al. 2009) causing a continuous gain in sales of alternatives such as alcohol-free beers (AFBs) over the past years. As a result, there is a strong interest of the beverage industry in low-alcoholic and alcohol-free products (Lehnert et al. 2009; NederlandseBrouwers, 2019). The definition of alcohol-free and nonalcoholic beers differs significantly between countries. While in

M. Ottens

m.ottens@tudelft.nl

1 Department of Biotechnology, Delft University of Technology, van der Maasweg 9, 2629 HZ Delft, The Netherlands

2 Global Innovation \& Research, Heineken Supply Chain BV, Burgemeester Smeetsweg 1, 2382

PH Zoeterwoude, The Netherlands the UK only beverages with an alcohol content of less than 0.05 vol.\% fall under this category, other European countries such as Germany allow beverages to contain up to 0.5 vol. $\%$ of alcohol (Brányik et al. 2012). In the USA, there is a clearer separation between 'alcohol-free', meaning no alcohol contained and 'nonalcoholic' beer, where the upper limit is 0.5 vol.\% (Montanari et al. 2009). In this review, the term alcohol-free is utilised.

Yet, the overall flavour and taste associated with AFBs is not comparable with its alcohol-containing equivalent (Sohrabvandi et al. 2010). Market studies conducted in the Netherlands, for instance, show that out of the population of Dutch consumers who do not consume non-alcoholic beverages, $60 \%$ state the sensorial defects as the reason (de Jongh and Peters 2014). Constituents of beer are numerous, amongst others it contains higher alcohols, esters, aldehydes, lactones, carboxylic acids and phenols, which contribute to the overall flavour of the drink (Catarino et al. 2009; Karlsson and Trägårdh 1997). In alcohol-free products, worty flavours are often considered over-pronounced. This perception is closely 
related to an elevated beer aldehyde content and results in an inferior sensory experience compared with a regular drink (Brányik et al. 2012).

The objective of this review is to give an overview on wort off-flavour profiles in AFBs and the underlying formation processes of aldehydes during brewing and downstream processing. Furthermore, aldehydes with the highest impact on taste perception are identified and the influence of the beer matrix constituents on sensory perception evaluated. In the second part of the review, a summary on current general removal technologies and state of the art in the brewing industry is given and future research opportunities are highlighted.

\section{Aldehydes as Flavour-Active Components in (Alcohol-Free) Beer}

\section{Relevant Flavour-Active Aldehydes in Beer}

Flavour profiles of alcoholic beers and AFBs are complex (De Schutter et al. 2008). A broad outline of most relevant flavouractive aldehydes in beer extracted from literature is given in Table 1. The list comprises 11 molecules, yet, most persistent and outstanding wort off-flavours are 3-methylbutanal (3MB), 2-methylbutanal (2-MB) (Beal and Mottram 1994) and methional (Perpète and Collin 1999a), where methional has $4.2 \mathrm{ppb}$, the lowest sensory threshold in beer amongst the three (Saison et al. 2009). 2-MB is often characterised as malty or almond like, while 3-MB also exhibits a chocolate character. The flavour of methional is related typically to a wort character and the smell of cooked potatoes (AndrésIglesias et al. 2016; Baert et al. 2012; Saison et al. 2009). Often, synergistic effects are observed. Currently, it is assumed that the unpleasant taste of AFBs results from the synergic interaction of 2- and 3-MB to sulphur-containing degradation products of methional (Blanco et al. 2016).

\section{Chemistry of Aldehydes in (Alcohol-Free) Beers}

Aldehyde formation in beer involves different substrates and mechanisms and mainly occurs during wort mashing and boiling (Blanco et al. 2016; De Clippeleer et al. 2010). The most important pathways are: (1) oxidation of unsaturated fatty acids by enzymatic oxidation, autoxidation and photo-oxidation, (2) Maillard reactions, (3) Strecker degradation, (4) degradation of bitter acids, (5) aldol condensation, (6) melanoidcatalysed oxidation of higher alcohols, (7) secondary autoxidation of aldehydes and (8) aldehyde secretion by fermenting yeast (Baert et al. 2012). Out of these, the most relevant mechanisms for the formation of 2- and 3-MB and methional dominance in alcohol-free products are further explained in the paragraphs below.
Maillard reactions or also called non-enzymatic browning reactions summarise all reactions of amines, amino acids, peptides or proteins with a reducing sugar. The reactions typically take place at temperatures above $50^{\circ} \mathrm{C}$ and a $\mathrm{pH}$ range of 4-7. Therefore, they are usually correlated with the application of heat and visible by a change in colour. Due to the complexity of possible reactions, the variety of Maillard products in beer is versatile and their chemical properties diverse (Saltmarch and Labuza 1982; Smit et al. 2009). The most important aldehydes formed through these reactions in beer production are furfural (FF) and 5-hydroxymethylfurfural (5-HMF), which serve as markers for the heat load impact on the mash, wort and beer (Carabasa-Giribet and Ibarz-Ribas 2000; ContrerasCalderón et al. 2008; De Schutter et al. 2008; Pereira et al. 2011). Their formation pathways are shown in Fig. 1. The carbonyl group of an aldose (pentose in case of FF, hexose in case of 5-HMF) reacts with an amine or amino group of an amino acid, peptide or protein to an imine, also called Schiff base. At beer pH (around 4.0-5.0) (Harrison et al. 1998), the chemical equilibrium favours the formation of 3-deoxyosone by elimination of a proton and an amine. Ring formation through condensation reaction then results eventually into the typical Maillard products FF (from pentose) and 5-HMF (from hexose) (Baert et al. 2012; Vanderhaegen et al. 2006).

Strecker degradation is defined as the heat-induced reaction of an $\alpha$-dicarbonyl or hydroxycarbonyl, such as glyoxal, methylglyoxal, diacetyl or 3-deoxyosone (Bravo et al. 2008; Chuyen 1998), with an amino acid according to the general mechanism outlined in Fig. 2a (Schonberg and Moubacher 1952). In the first step of the reaction, an unstable hemiaminal is formed by the nucleophilic addition of the unprotonated amino group to the carbonyl group. The reversible elimination of water and consequent irreversible decarboxylation results in the formation of an imine zwitter ion. The addition of water yields an amino alcohol, which in turn degrades into an $\alpha$ ketoamine and the so-called Strecker aldehyde (Baert et al. 2012; Rizzi 2008; Yaylayan 2003).

Strecker degradation is generally thought to be related to the chemistry of reducing sugars. During the Maillard reaction, the Schiff base can rearrange to the a so-called Amadori product (Hodge 1955; Hodge and Rist 1953; Yaylayan 2003), as shown in Fig. 1, which then degrades to the $\alpha$-dicarbonyl component (Smit et al. 2009). However, it has been shown that other reactive carbonyls such as lipid-derived carbonyls or quinones from polyphenol oxidation also contribute to the formation of Strecker aldehydes (Delgado et al. 2015; Hidalgo and Zamora 2004; Hidalgo et al. 2013; Rizzi 2008). When testing the capacity of 20 phenolic derivatives to form Strecker-type degradation products of phenylalanine and phenylglycine methyl ester, results indicated that polyphenols are potent to induce the reaction in absence of added oxidants (Delgado et al. 2015). One mechanism proposed for the formation of Strecker aldehydes in presence of reactive carbonyls 
Table 1 Summary of relevant flavour-active aldehydes, their sensory threshold in beer (Meilgaard 1975; Saison et al. 2009) and sensory descriptor (Andrés-Iglesias et al. 2016; Baert et al. 2012; Chambers Iv and Koppel 2013; Kroh 1994; Saison et al. 2009)

\begin{tabular}{|c|c|c|}
\hline Name (group) & Threshold $\left(\mu \mathrm{g} \mathrm{L}^{-1}\right)$ & Description \\
\hline Acetaldehyde (linear aldehyde) & $1114-25,000$ & - Green apple, fruity \\
\hline 2-Methylpropanal (Strecker aldehyde) & $86^{\mathrm{a}}-1000$ & $\begin{array}{l}\text { - Produced through Strecker degradation of valine or oxidative degradation } \\
\text { of isohumulones (hops component) } \\
\text { - Grainy, varnish, fruity }\end{array}$ \\
\hline 2-Methylbutanal (Strecker aldehyde) & $45-1250$ & $\begin{array}{l}\text { - Produced through Strecker degradation of isoleucine or in presence of oxygen } \\
\text { - Almond, apple-like, malty }\end{array}$ \\
\hline 3-Methylbutanal (Strecker aldehyde) & $56^{\mathrm{a}}-600$ & $\begin{array}{l}\text { - Produced through Strecker degradation of leucine or in presence of oxygen } \\
\text { Malty, chocolate, cherry, almond }\end{array}$ \\
\hline Hexanal (linear aldehyde) & $88-350$ & $\begin{array}{l}\text { - Product from fatty acid oxidation } \\
\text { - Green, grassy }\end{array}$ \\
\hline Methional (Strecker aldehyde) & $4.2-250$ & $\begin{array}{l}\text { - Produced through Strecker degradation of methionine } \\
\text { - Cooked potatoes, worty }\end{array}$ \\
\hline Phenyl acetaldehyde (Streckeraldehyde) & $105-1600$ & $\begin{array}{l}\text { - Produced through Strecker degradation of phenyl alanine } \\
\text { - Hyacinth, flowery roses }\end{array}$ \\
\hline Trans-2-nonenal (linear aldehyde) & $0.03-0.11$ & $\begin{array}{l}\text { - Reaction between heptanal and acetaldehyde or auto-/enzymatic } \\
\text { oxidation of linoleic } \\
\text { - Cardboard, papery, cucumber }\end{array}$ \\
\hline Benzaldehyde aromatic aldehyde & $515-2000$ & $\begin{array}{l}\text { - Produced in presence of oxygen } \\
\text { - Almond, cherry stone }\end{array}$ \\
\hline Furfural (heterocyclic aldehyde) & $15,000^{\mathrm{a}}-150,000$ & $\begin{array}{l}\text { - Product of Maillard and caramelisation reaction (heat indicator) } \\
\text { - Indicator of flavour instability in beer } \\
\text { - Caramel, bready, cooked meat }\end{array}$ \\
\hline $\begin{array}{l}\text { 5-Hydroxy-methyl-furfural } \\
\text { (heterocyclic aldehyde) }\end{array}$ & $35,784^{\mathrm{a}}-1,000,000$ & $\begin{array}{l}\text { - Product of Maillard reaction and caramelisation } \\
\text { - Bready, caramel }\end{array}$ \\
\hline
\end{tabular}

${ }^{\text {a }}$ Odour threshold

derived from lipid oxidation is shown in Fig. 2b. The reaction is initiated by the formation of an imine from the amino acid and the reactive carbonyl under elimination of water. After consequent decarboxylation due to an electronic rearrangement, the molecule forms a second imine, which then hydrolyses to the Strecker aldehyde. The 'by-product' of this reaction in turn is unstable and initiates further reactions with amino acids (Hidalgo and Zamora 2016).

The above overview on Strecker aldehyde formation in beer is only a rough insight on involved reactions and pathways. Kinetic modelling of the involved reaction during wort boiling has been attempted, but it is still in its infancy (Huang et al. 2017).

\section{Origin of Aldehyde Formation During Regular and Alcohol-Free Beer Brewing}

The common cause of the different compositions and hence taste of AFBs is the deviating brewing process of AFBs compared with regular beer. Figure 3 provides an overview on the simplified brewing process of regular beer and the related change in aldehyde content in the product. During the brewing process, the most significant change in wort flavour concentration is observed in mashing, fermentation and maturing (Briggs et al. 2004), but some formation of the compounds already occurs during kilning in the malting step (Yahya et al. 2014). Thereby, the heat subjected to the grains to stop the germination process induces Maillard reactions, caramelisation, Strecker degradation as well as fatty acid oxidation. After malting, the grist is added to the mash mixer and combined with the brewing liquor. Consequently, a welldefined mashing procedure is followed, where the enzymatic conversion of polysaccharides to short sugars takes place. In parallel, aldehydes are again formed through the head-induced Maillard reactions, caramelisation, Strecker degradation and oxidation of fatty acids. In the following step of wort boiling, the hop is added and contained $\alpha$-acids are isomerised. Due to the high heat input, the same heat-induced reactions take place, but at the same time, the formed flavours are evaporated and therefore removed from the wort. In the subsequent fermentation, yeast metabolises the fermentable sugars in the wort as well as most aldehydes to their respective alcohol (Boulton 2013; Briggs et al. 2004). The final product contains only very small amounts of wort flavour.

For the production of AFBs, several process strategies are pursued. These include biological methods such as fermentation-free brewing, dilution, restricted alcohol fermentation and physical dealcoholisation techniques like thermal or 


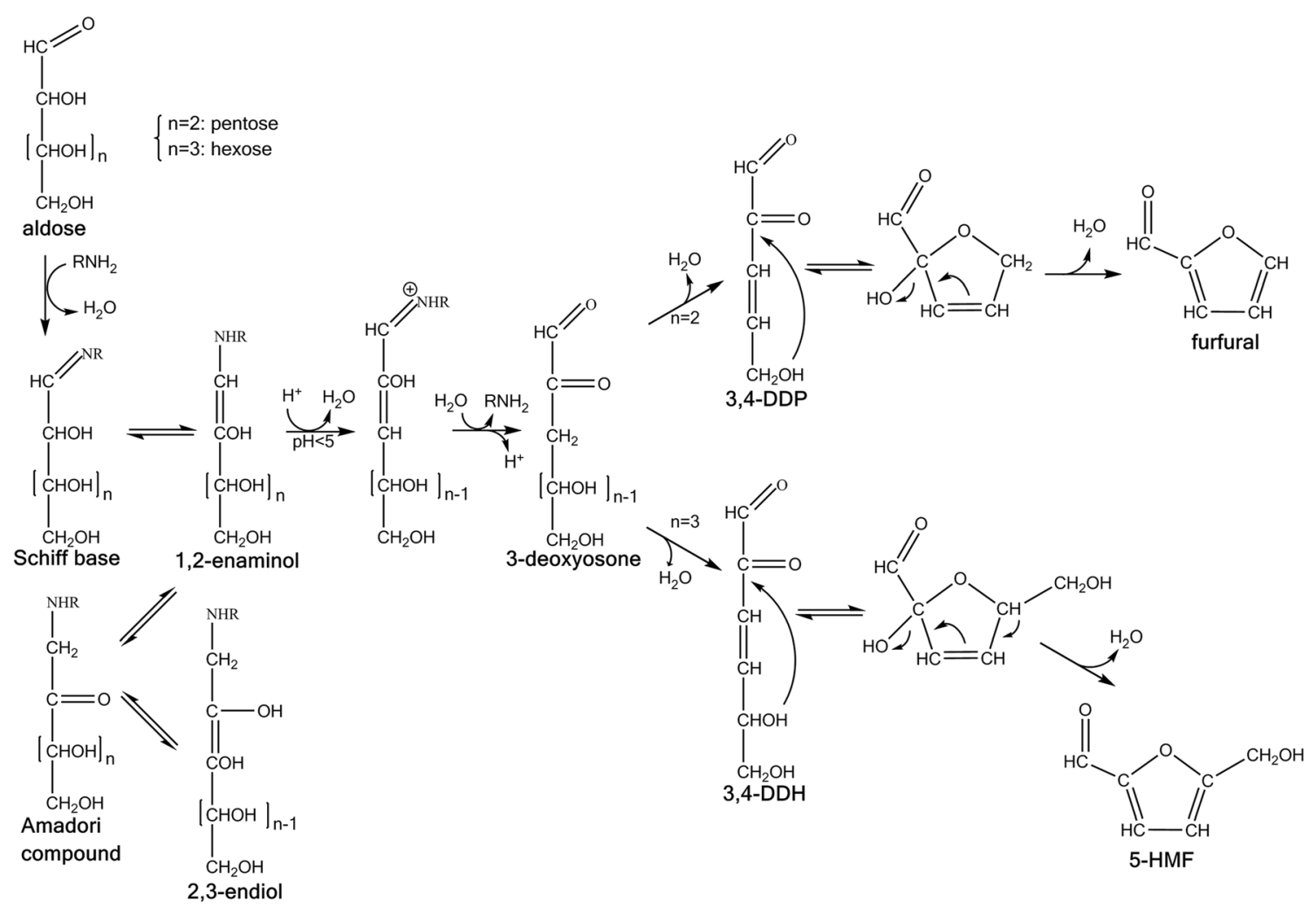

Fig. 1 Overview on Maillard reactions leading to the formation of FF and 5-HMF (Baert et al. 2012; Vanderhaegen et al. 2006)

membrane technologies. An overview on employed production technologies and their respective aldehyde levels is given in Fig. 4 (Brányik et al. 2012; Sohrabvandi et al. 2010).

While physical methods include a regular fermentation and the downstream removal of the produced alcohol, the biological methods follow the strategy of restricting ethanol production during fermentation, allowing for flavour development and off-flavour removal to a certain extend. These fermentations can be carried out in batch or continuous operation. Different practices are under investigation and proposed in the literature. The most common methods include the cold contact procedure, arrested fermentation, the usage of special yeast strains (Montanari et al. 2009) and the reduction of fermentable fractions to non-fermentable fractions by a changed mashing process (Sieben and Zastrow 1991). Physical methods fall into two categories, which are thermal dealcoholisation methods and membrane-based dealcoholisation technologies. Thermal dealcoholisation systems include evaporators, rectification units and stripping columns. Membrane-based separations use the principle of dialysis or reverse osmosis, but are currently developing in the newer applications of pervaporation (Brányik et al. 2012) and osmotic distillation (Russo et al. 2013).

As diverse as the production processes known for brewing AFB are the related organoleptic defects of AFBs (Brányik et al. 2012). A major problem in dealcoholised beers described in literature is that during the process, not only ethanol is removed but also aroma compounds, which contribute to the organoleptic characteristics of the beer. Thereby, the ester and higher alcohol content is strongly affected. The highest loss is observed for thermal dealcoholisation techniques, while membrane-based processes have the lowest reduction in volatile aromas compared with the original (Brányik et al. 2012). Furthermore, if thermal methods of dealcoholisation are applied, alternation by the impact of heat can occur, causing the appearance of heat-induced off-flavours such as 5-HMF or FF. Beverages produced by restricted fermentation or complete elimination of the fermentation process often exhibit an unpleasant taste of sweet wort due to the fact that yeast cannot sufficiently reduce the high aldehyde concentration in the wort at given operating conditions (Montanari et al. 2009). Other process alternatives such as dealcoholisation by gas desorption (Hertel 2011), extraction with supercritical $\mathrm{CO}_{2}$ or adsorption with silica gels have been developed but are of no industrial relevance (Müller et al. 2016).

\section{Impact of Alcohol-Free Beer Composition on the Perception of Wort Off-Flavours}

At a closer look, the problem is not only the loss of flavour but also the loss of balance in the flavour profile of the beer (Brányik et al. 2012; Narziss et al. 1993) and the change in the composition of the beer matrix. Consequently, even if the 
<smiles>[R]C(=O)C([R2])=O</smiles><smiles></smiles>

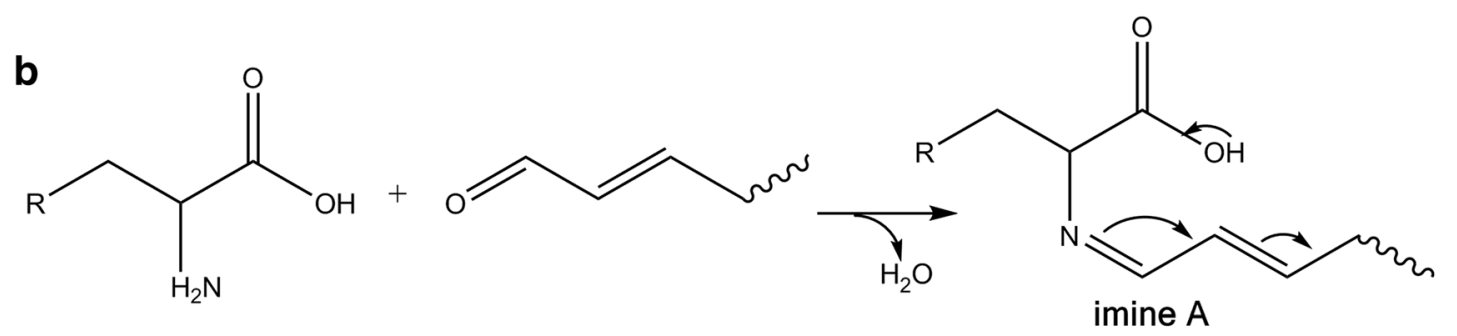

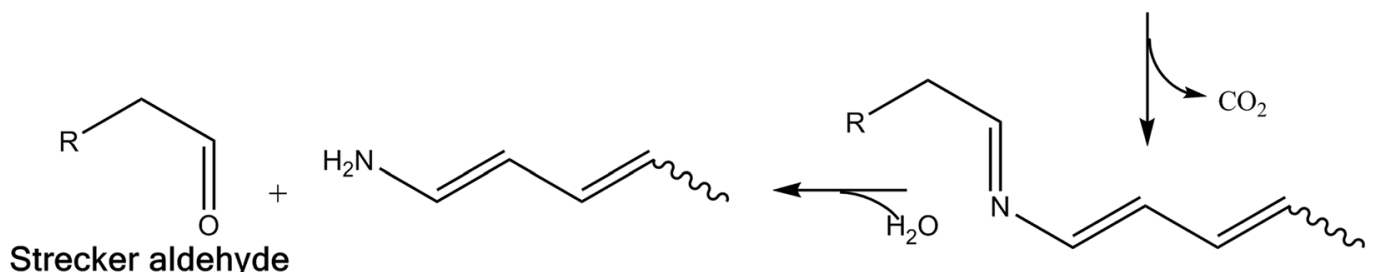

Fig. 2 a General formation mechanism of Strecker aldehydes from an amino acid and $\alpha$-dicarbonyl group (Baert et al. 2012; Schonberg and Moubacher 1952). b Proposed mechanism of formation of Strecker

same exact composition of aroma-active compounds in the AFB as in the original could be achieved, the beer would still have an unbalanced taste. This is caused by the change in the thermodynamic properties of the beer matrix (Conner et al. 1998; Philippe et al. 2003). Literature provides thresholds for the perception of worty off-flavours for regular beer. However, it has been proven that these thresholds do not hold for an AFB matrix due to three effects:

1) The absence of ethanol as a matrix component increases the polarity of the matrix and hence results in an increased partition coefficient for more nonpolar aldehydes. If compared, the retention of aldehydes in regular beer ranges between 32 and 39\%, while a non-alcoholic beer of 0.5 vol. \% could only retain $8-12 \%$ of measured aldehydes (Brányik et al. 2012; Perpète and Collin 2000c). Because most flavour molecules are detected by the nose, the taste of a aldehydes from amino acids in presence of lipid-derived reactive carbonyls (Hidalgo and Zamora 2016)

beverage results primarily from its vapour phase (Normand et al. 2004). Thus, the increased volatility of aldehyde causes the worty character in AFBs to be over-pronounced, which consequently causes a poor taste experience (Blanco et al. 2016; Perpète and Collin 2000c).

2) The absence of positive flavours such as esters and higher alcohols in AFB leads to a more pronounced perception of the worty aroma. Fruity esters have been shown to have a significant masking effect for wort flavours in beer, i.e., on addition of an extra amount of 300 ppb isoamyl acetate, the flavour threshold of 2-MB and methional in regular beer increased by 250 and $40 \%$, respectively (Saison et al. 2009).

3) The presence of higher concentrations of monosaccharide sugars typically observed in AFBs causes a 'salting out' effect for aldehydes from the beer matrix, which leads to a further increase in the perceived wort 


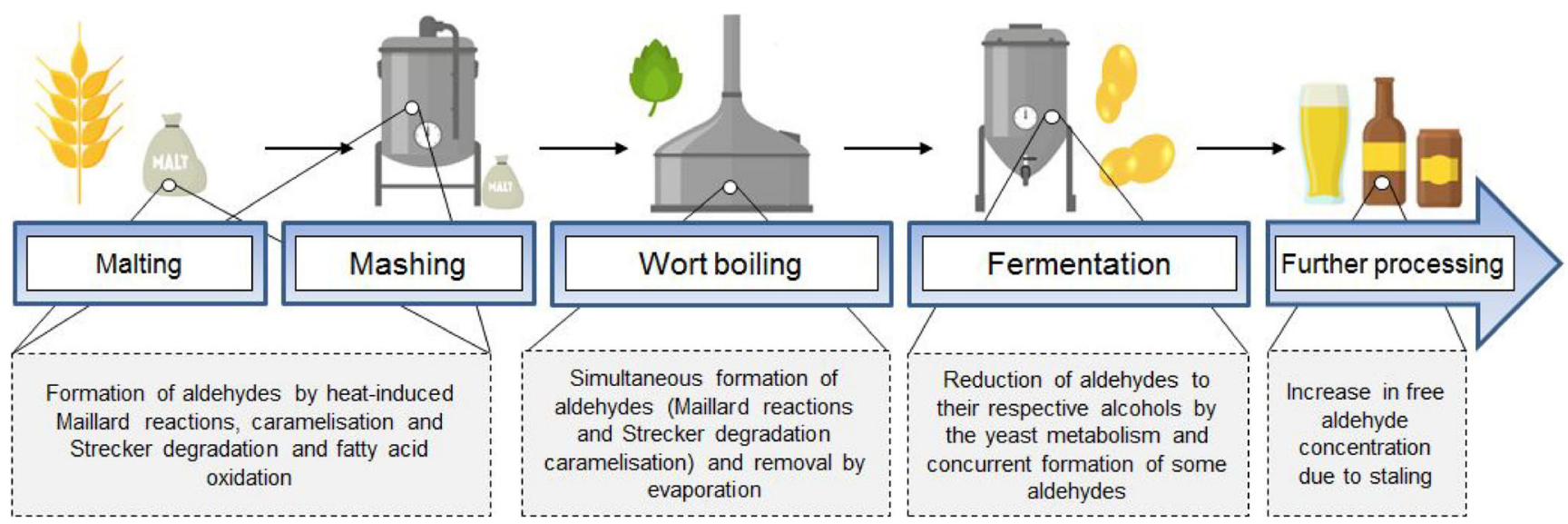

Fig. 3 Overview on simplified brewing process and the related impact on the aldehyde concentration

flavour. In a sensory evaluation of a model AFB, methional could be detected by $80 \%$ of the test panel at concentrations as low as $0.1 \mathrm{ppb}$ (Perpète and Collin 2000c). Although this value is not a sensory threshold for AFB, it is an indication for the fact that methional can be perceived at significantly lower concentrations than its sensory threshold of 4.2-250 ppb for regular beer stated in literature (Meilgaard 1975; Saison et al. 2009).

Besides these three factors, other matrix components influence the retention of aldehydes in beer. Studies suggest that polyphenols, such as catechin impact the volatility of not only esters but also aldehydes (Dufour and Bayonove 1999; Jung et al. 2000). The decrease in the activity coefficients of isoamyl acetate, ethyl hexanoate and benzaldehyde at a catechin concentration of $10 \mathrm{~g} \mathrm{~L}^{-1}$ was observed to be 10 15\% (Dufour and Bayonove 1999). Typically, catechin and epicatechin concentrations in beer are found to be below $10 \mathrm{mg} \mathrm{L}^{-1}$ (Li and Deinzer 2009) but can reach up to $30 \mathrm{mg}$ $\mathrm{L}^{-1}$ (McGuinness et al. 1975). Hence, in this case, the impact of catechin on aldehyde perception is at this concentration insignificant; however, other polyphenols might have a more pronounced effect. Furthermore, it is known that amino acids can readily bind aliphatic aldehydes. In particular, cysteine is involved in the formation of thiazolidine carboxylic acids (Maier 1973; Maier and Hartmann 1977). Baert et al. (Baert et al. 2015a) showed that aldehydes in beer tend to form adducts with cysteine and bisulphite at beer $\mathrm{pH}$ (Baert et al. 2015a; Baert et al. 2015b). Consequently, two strategies can be pursued to decrease the perception of worty off-flavours.

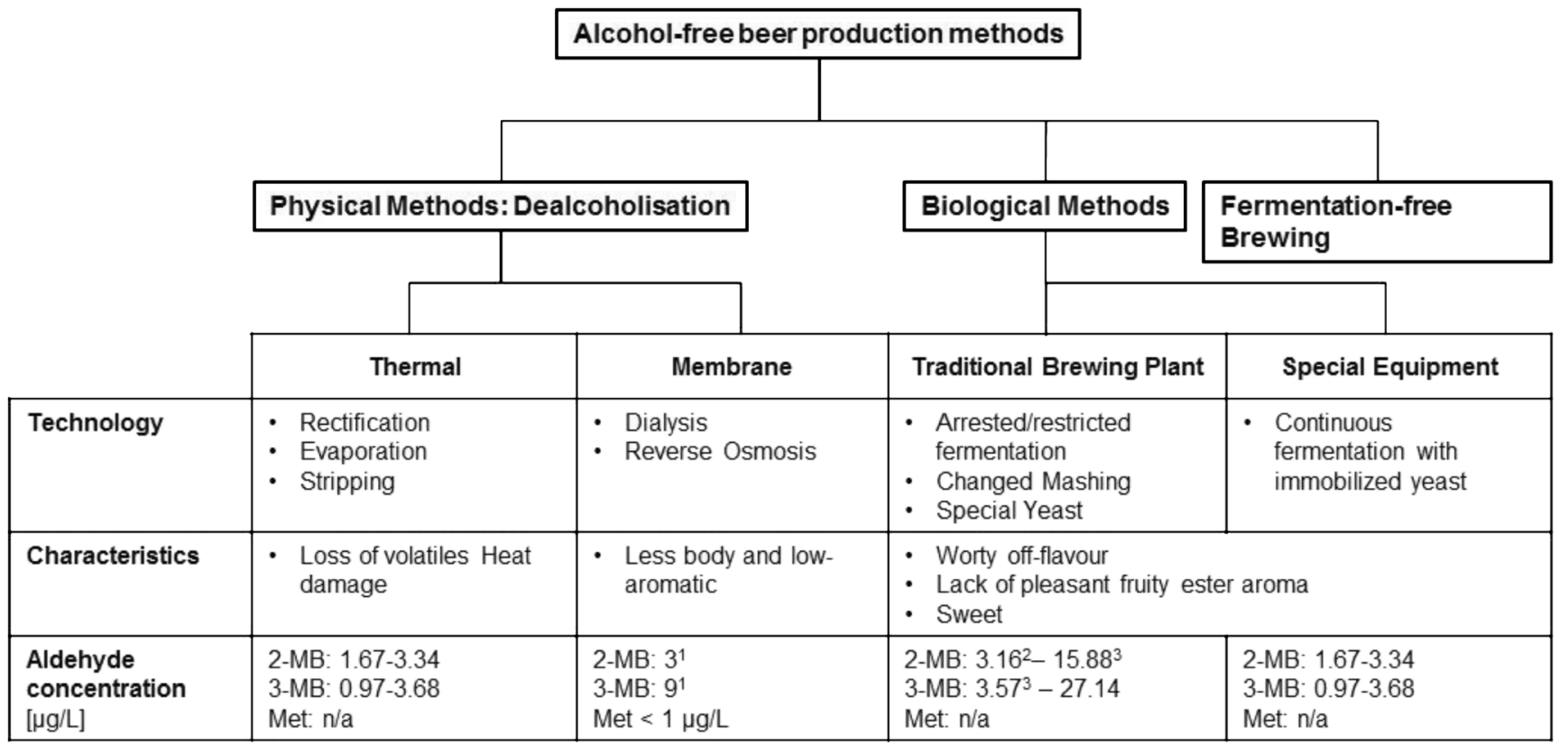

${ }^{1}$ close to detection limit of applied technique; ${ }^{2}$ short fermentation; ${ }^{3}$ special yeast

Fig. 4 Schematic classification of AFB production methods adapted from Brànyik et al. (2012) and Sohrabvandi et al. (2010; (Müller et al. 2016)) and characteristics (Blanco et al. 2016) and respective levels of relevant aldehydes (Andrés-Iglesias et al. 2016) 


\section{Methods of (Selective) Aldehyde Removal}

The complex nature of aldehyde chemistry implies that removing educts such as methionine from the feedstock would decrease the concentration of the corresponding aldehyde to an extend, but will possibly not bring the desired reduction in aldehyde concentration. The following paragraphs will thus rather focus on scouting technologies for the direct removal of aldehydes. When targeting the aldehyde off-flavours, the challenge lies in choosing for a high selectivity over other beer constituents thus preserving the natural nutritional value and taste of an AFB (Müller et al. 2016). Figure 5 shows possible mechanisms to accomplish a selective removal of aldehydes from AFBs. The removal can either be based on physical properties of the molecules, such as size and volatility, or based on interactions with other molecules and surfaces, where the selectivity is defined by the specificity of the interaction. Through a thorough study of state of the art in literature, patented technologies for aldehyde removal and the status quo in brewing industry in this work, technologies making use of the removal mechanisms were compiled as depicted in Fig. 6 and analysed for their selectivity in the following paragraphs.

\section{General Technologies for Aldehyde Removal}

\section{Adsorptive Removal: Physisorption on Hydrophobic Resins and Activated Carbon}

One molecular property often exploited, e.g. in pharmaceutical industry for separation of proteins and antibodies is the

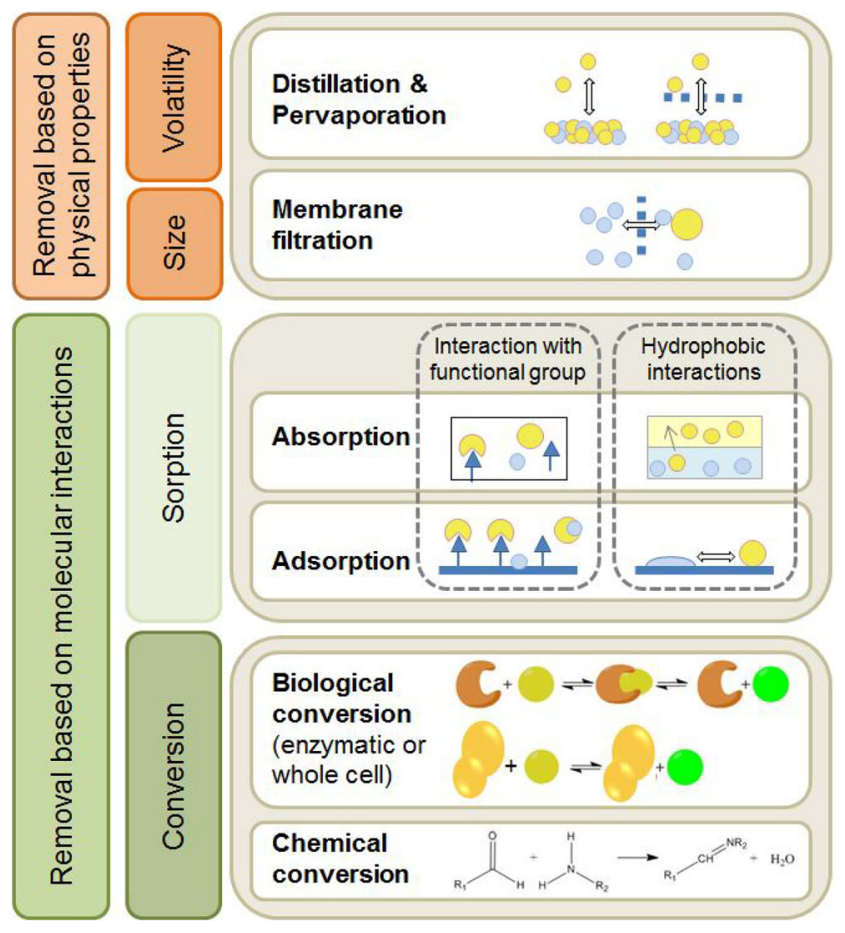

Fig. 5 Possible mechanisms for the removal of aldehydes from AFBs hydrophobicity of a compound (Lu et al. 2009). Since aldehydes such as FF can act as fermentation inhibitors, its removal from biomass hydrolysate by adsorption on the polymeric resins Amberlite XAD-4 and XAD-7 and its desorption by elution with ethanol was studied. Results showed XAD-4 performed superior to XAD-7, which is explained by the higher hydrophobicity of the polystyrene-divinylbenzene copolymer of XAD-4, when compared with the methacrylate backbone of XAD-7. At a temperature of $30^{\circ} \mathrm{C}$, the $\mathrm{FF}$ concentration could be reduced by factor $100-500$, from $1-5$ to $0.01 \mathrm{~g} \mathrm{~L}^{-1}$, and desorption was proven to be feasible with ethanol (Weil et al. 2002). In a similar context, the removal of FF and HMF from a biomass hydrolysate by Amberlite XAD- 8 was measured. After $1 \mathrm{~h}$ of incubation ( $8.0 \mathrm{~g}$ of resin in $50 \mathrm{~mL}$ hydrolysate), the remaining amount of aliphatic acids, HMF, FF, phenols and ketones was determined. The FF concentration was reduced to $35-41 \%$ of the initial concentration. The reduction of HMF showed to be dependent on the $\mathrm{pH}$. The reduction was found to be 20 and $42 \%$ at $\mathrm{pH} 5.5$ and 10.0 , respectively (Nilvebrant et al. 2001). This might be due to the fact that the removal of phenols is more efficient at lower $\mathrm{pH}$ leaving less capacity for HMF.

In another lab-scale experiment, Amberlite XAD-2 and XAD-4 were compared with the adsorption behaviour of adsorbent manufactured through post-polymerisation crosslinking of swollen chloromethylated gel-type and macroreticular copolymers of styrene and divinylbenzene. For the tests, FF uptake from an aqueous solution was studied. The researchers found that the microporous structure of the self-manufactured resin was superior for removing $\mathrm{FF}$ at low concentrations $(<2 \mathrm{wt} . \%)$; however, due to the higher surface area, the macroporous adsorbent XAD-4 was performing more efficiently at higher FF concentrations (Jeřábek et al. 1994).

The kinetics and impact of several experimental parameters on FF adsorption on activated carbon (AC) in aqueous phase was investigated by Sahu et al. (Sahu et al. 2008). The removal step was found to follow pseudo-second-order kinetics and showed optimal performance at $\mathrm{pH} 5.9$ and an adsorbent dosing of $10 \mathrm{~g} \mathrm{~L}^{-1}$ solution. The experimental data could be best characterised by the Redlich-Peterson isotherm model (Sahu et al. 2008).

Hydrophobic resins and AC have also been subject of research for applications in food and beverage industry (Aimoto et al. 2011; Lucas et al. 2004; Medeiros et al. 2006; Ottens et al. 2016; Rojas et al. 2006; Saffarionpour et al. 2016; Zhang et al. 2010). For instance, the selective recovery of key aroma compounds from roasted coffee was investigated for quality optimisation of the final product. FF and ethyl acetate were adsorbed from supercritical $\mathrm{CO}_{2}$ on $\mathrm{AC}$, and the impact of process parameters was studied. The adsorption showed to be dependent on processing temperature and $\mathrm{CO}_{2}$ density (Lucas et al. 2004). A similar study was conducted by 


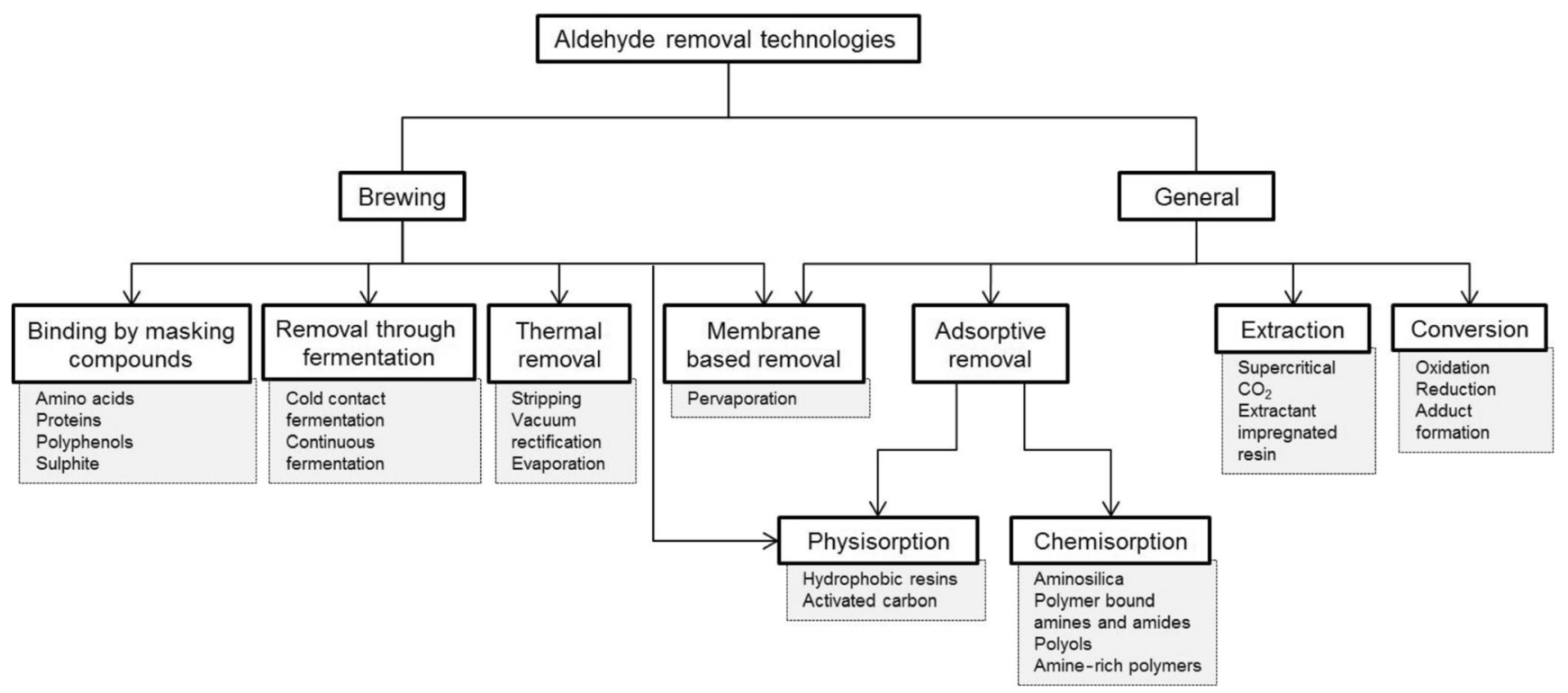

Fig. 6 Overview on existing removal technologies for aldehydes

Canteli et al. (Canteli et al. 2014) to investigate the fixed-bed adsorptive removal of the coffee flavour benzaldehyde from an aqueous solution with granular AC (Canteli et al. 2014). A comparison of two hydrophobic resins with $\mathrm{AC}$ was conducted to test the feasibility of recovering microbiologically produced volatile aroma compounds from off-gas streams during a fermentation. The experiments were carried out at lab- and semi-pilot scale. Major volatiles identified during the experiments were ethanol, acetaldehyde (AcA), ethyl acetate, ethyl propionate and isoamyl acetate. Three different resins AC, Tenax-TA, and Amberlite XAD-2 were tested to evaluate their suitability for recovering aromas from the gaseous stream. While the AC exhibited poor recovery, the Amberlite XAD2 resin adsorbed all components present in the headspace. Interestingly, Tenax-TA showed a higher selectivity for AcA over contained esters and ethanol (Medeiros et al. 2006). In a recent study of Müller-Maatsch et al. (Müller-Maatsch et al. 2019), the removal of glucosinolates and volatiles, e.g. aldehydes, from an anthocyanin-rich extract of red cabbage was investigated. From the studied adsorbent and flocculants (Amberlite XAD $16 \mathrm{HP}$, polyamide, chitosan, and lignosulfonate), Amberlite, chitosan and lignosulfonate reduced the aldehyde content. However, also other molecules such as fatty acids, sulphides, glucosinolates and the isothiocyanates were taken up (Müller-Maatsch et al. 2019).

\section{Adsorptive Removal: Chemisorption on Aminated Materials}

Amine groups are known to form bonds with aldehydes. The so-called imine formation shown in Eq. 1 (Zhu et al. 2006) is particularly favoured at $\mathrm{pH} 4-5$ (Neuman 2006); therefore, this system is well applicable to beer or wort feedstocks.

$$
\begin{aligned}
\mathrm{R} & -\mathrm{CHO} \text { (aldehyde) }+\mathrm{H}_{2} \mathrm{NR}^{\prime}(\text { primary amine }) \rightarrow \mathrm{RHC} \\
& =\mathrm{N}-\mathrm{R}^{\prime}(\text { imine })+\mathrm{H}_{2} \mathrm{O}
\end{aligned}
$$

Aminosilica resins have been utilised to remove aldehydes from complex mixtures. A study of Drese et al. (Drese et al. 2011) tested solid aminosilica adsorbents, namely pore-expanded SBA-15 functionalized with 3a minopropyltrimethoxysilane, 3-(2-aminoethyl)aminopropyltrimethoxysilane and 3-[2-(2-aminoethyl)amino-ethyl] aminopropyltrimethoxysilane, on a model solution ('bio-oil') of phenols, cyclohexane, hexanol, aldehydes, ketones and diketones. Light alcohols were not investigated in these experiments as they are considered nonreactive with aliphatic amines. The adsorption showed to be selective for aldehydes and some ketones and the adsorbent capacity increased with primary amines content and increasing temperature (Drese et al. 2011). This is expected as imine formation occurs only with primary amines and the reaction is preferred at higher temperature. The selectivity of aldehydes over ketones can be explained by the fact that aldehydes are considerably more reactive than ketones (Carey and Sundberg 2007). The reactivity of aldehydes with aminosilica depends strongly on their chemical functionality, but for all tested aldehydes at least moderate removal was achieved. Partial resin regeneration was proven to be feasible by acid hydrolysis of the adsorbent, however, resulted in a significant loss in reactivity (Drese et al. 2011).

A similar principle is exploited in US patent 7041220 B2 'Method of use for aldehyde removal' in which a solid surface with a primary amine function is used as an adsorbent to remove environmentally hazardous aldehydes such as orthophthalaldehyde from waste water streams. Solid surfaces 
include silica and also polymer-linked systems. Different aldehyde scavengers can be attached to the solid surface. The extended chain length of the amine bearing residual may help to decrease steric hindrance in particular for voluminous aldehydes. On the contrary, if smaller aldehydes are targeted, a short chain length increases the selectivity for low molecular compounds. Depending on the scavenger properties, different aldehydes are targeted. The patent does not give indications for recycling the adsorption material and furthermore mentions that during the aldehyde removal process, if executed with silica, other compounds are also removed by means of hydrogen-bonding principles or physical filtration mechanisms. Besides attaching scavengers to polymeric backbones, polymeric amino group-rich systems such as chitosan can be made of use for aldehyde removal (Zhu et al. 2006). Chitosan is a naturally occurring amine-rich polymer generally regarded as safe (GRAS) by the U.S. Food and Drug Administration (FDA 2002), which has been found to react according to Eq. 1 with aldehydes to form imines (Monteiro and Airoldi 1999).

One more application of aminosilica is the improvement of air quality by removing volatile organic compounds such as airborne formaldehyde (Ewlad-Ahmed et al. 2012; Lee et al. 2008b; Nomura and Jones 2013; Strommen and Gesser 2011; Zhu et al. 2012). The first patent was filed by Gesser in 1985 (Gesser 1985; Gesser 1990), but since then many others have followed (Koller et al. 1999; Nomura and Jones 2013). Zhu et al. (Zhu et al. 2012) functionalised uniform mesoporous silica SBA-15 with N-(2-amino-ethyl)-3-aminopropyl]trimethoxysilane and found the so obtained adsorbent to have a good chemoselectivity for formaldehyde (Zhu et al. 2012). When systematically investigating the adsorption of airborne aldehydes on aminosilica resins, it was found that the resin capacity was related to the structure of the amine moieties as well as the site density. Primary amines showed to be the most potent aldehyde adsorbent for AcA, hexanal and formaldehyde from air. Aminosilica with a primary amine function showed an around twofold higher loading for form- and AcA compared with secondary amine-functionalised aminosilica. The capacity for hexanal, however, was only increased by $14 \%$. It is speculated that this can be explained by the slower diffusion of hexanal into the functional material. In the studies performed, it was found that most formaldehyde was adsorbed within the first hour, while AcA and benzaldehyde took more than $10 \mathrm{~h}$ (Nomura and Jones 2013). Furthermore, it was observed that there is an optimal amine loading for maximising the (gaseous) formaldehyde adsorption. Medium loaded aminosilica are most effective as at higher loadings steric hindrance is suspected to counteract efficient imine formation (Nomura and Jones 2013; Sae-Ung and Boonamnuayvitaya 2008).

Another potent aldehyde scavenger employed as abatement of indoor pollutants is polyamine polyethylenimine (PEI) (Gesser 1985; Gesser 1990; Gesser and Fu 1990). Yet, the compound finds vast application in other fields. PEI is employed in active materials in food packaging in order to enhance food freshness (Suloff 2002). DuPont patented PEI as an aldehyde scavenger resin in US 5413827, which can be incorporated in the packaging material as cap liner, sticker or package insert. An outer material such as high density polyethylene fibres are permeable for aldehydes at a desired rate and enclose the aldehyde scavenger module. PEI is preferably not heavily branched and has a low percentage in tertiary amines. The molecular structure of the aldehyde scavenger is $\mathrm{H}-\left(-\mathrm{CH}_{2}-\left(\mathrm{CH}_{2}\right)_{n}-\mathrm{NH}-\right)_{m}-\mathrm{H}$, where $n$ equals most preferably 1 and $m$ is bigger than 100 (Brodie and Visioli 1995; Suloff 2002). The authors do not give an explanation for the underlying mechanisms, but the study of the sorption kinetics of hexanal performed by DelNobile et al. (DelNobile et al. 2002) suggest that "the sorption process of hexanal in the investigated aldehyde scavenger film could be described in terms of the hypothesised 'sorption-reaction' mechanism" (DelNobile et al. 2002).

The compound is furthermore described as by-product adsorber for oxygen scavenging packaging material systems in US patent 5942297, but the invention also includes other polymeric amines such as polymers and copolymers of allylamine (or diallylamine), vinyl amine and vinyl pyridine and chitosan (Speer et al. 1999). In a similar invention (US 6057013), the use of pentaethylene hexamine, triethylene tetraamine, and polyvinyl oxazoline for aldehyde scavenging is patented (Ching et al. 2000).

Another effective aldehyde scavenger type frequently used in packaging industry is polyamides. Amides are long known to react with aldehydes in a condensation reaction (Mehra and Pandya 1938; Noyes and Forman 1933; Pandya and Sodhi 1938), but depending on the conditions applied, the reaction of aldehydes with amides can result in numerous products (Tejedor and Garcia-Tellado 2007). In order to reduce byproducts, in particular AcA, from ozonated water during storage in the bottle, a functional material consisting of a polyester/polyamide blend for lessening the concentration of AcA is described in US patent 6042908 (Long et al. 2000). The mechanism is believed to be the formation of an imine as described in Eq. 1 (Suloff 2002). A series of aldehyde scavengers was tested for the application of capturing AcA from the gas phase on a beverage bottle. Anthranilamide, anthranilic acid and AC achieved a reduction of up to $98 \%$ when compared with the control sample; however, selectivity is not discussed (Howell and Ponasik 2008).

An effort of producing such a polyamides resin at low cost to capture aldehydes and ketones was made by de Oliveira et al. (de Oliveira et al. 2015). The authors synthesised the isoniazid-functionalized resin Amb15-iso by reacting commercially available Amberlyst 15 with isoniazid, which is an antibiotic commonly used in the treatment of tuberculosis. Its performance was tested for acetone and isobutyraldehyde in 
different solvents. The overall amount of ketone removed increased with increasing polarity of the solvent and the adsorption was hence best in water. The resin showed to be more efficient for the removal of isobutyraldehyde than for acetone, where the maximum removal was $80 \%$ after less than $20 \mathrm{~min}$ in ethanol and hexane. The trend of increasing removal efficiency with increasing polarity could only partially be reproduced for the aldehyde and water could not be tested as a solvent due to the low miscibility of isobutyraldehyde. The resin was shown to be reusable at least for a second cycle of adsorption (de Oliveira et al. 2015).

In the field of organic chemistry, a separation medium was developed to particularly target aromatic aldehydes, comprising polymer-supported benzylhydrazines to react according to Eq. 1 (Zhu et al. 2004). Organic chemists also studied a copoly(styrene-divinylbenzenesulfonylhydrazine) resin containing the chemical functional group of sulphonamides, which was characterised and tested for scavenging aldehydes, ketones and glucose in water. These molecules are presumably bound by forming the corresponding sulfonylhydrazone derivatives. For ketones, it was observed that the extension of the reaction depended on the molecular size, ranging from $>90 \%$ for small ketones to less than $2 \%$ for bulky ones such as camphor. The reaction products could be displaced by the addition of pyruvic acid (Emerson et al. 1979). Polystyrenebased sulfonylhydrazine resin was also proposed as adsorbent to remove impurities from a pharmaceutical product. At a phase ratio of 50, the achieved aldehyde reduction amounted to $85 \%$ without adding additional impurity to the product (Welch et al. 2003).

Similarly, a polystyrene resin functionalized with sulphonamides and pendant oligo(ethyleneimines) was developed to separate aldehydes from hydrocarbon mixtures. Biçak et al. (Biçak et al. 1997) studied the sorption behaviour of AcA, benzaldehyde and salicylaldehyde on such an oligo(ethyleneimines) polymeric resin, which was found to be second order kinetics. The sorption process is valid for all aromatic aldehydes, however, aliphatic aldehydes, which carry an $\alpha$-hydrogen can also form aldol products in solution. In the case of aliphatic aldehydes, their aldol products are also adsorbed, which limits their recovery. Depending on the amine content of the resin, two different mechanisms for aldehyde scavenging, namely the formation of a Schiff base and five-membered imidazoline rings, are observed as shown in Fig. 7. The regeneration of the resins by dilute acid solution treatment (aldehydes stay intact) is possible due to good stability of the sulfamide bond towards acid-base hydrolysis. Acetone and alkyl halogenides were observed to interfere in the sorption process (Biçak and Șenkal 1997).

In continuation of this work, 1,2-diaminoethane containing epoxy resins was studied for aldehyde separation. 1,2-Diaminoethane units function as the polymeric analogue of Wanzlick reagent, which forms imidazolines in a condensation reaction. Both studies describe the removal of aldehydes from organic mixtures, using watermiscible solvents such as methanol and dioxane. The sorption is reported to be very slow for unpolar solvents due to the hydrophilicity of the polymer (Biçak et al. 1999).

\section{Adsorptive Removal: Chemisorption on Polyols Functionalized Materials}

Yet, another example for effective aldehyde elimination by a packaging material is integration of polyols into the polymer material. Aldehydes are converted to an acetal by the reversible nucleophilic addition reaction of the aldehyde (or ketone) with a polyol such as sorbitol, mannitol or alkoxylated polyols. The formed acetal exhibits a lower volatility than aldehydes and is therefore less detectable in food products (Al-Malaika 2000; McNeely and Woodward 1993; Wiegner et al. 2001). The exemplary reaction of valeraldehyde with D-sorbitol is given in Fig. 8. Suloff (Suloff 2002) demonstrated in his work that the integration of D-sorbitol into poly(ethylene terephthalate) reduced the total aldehyde content by half during the storage of a model solution of $\mathrm{pH}$ 3.6. Furthermore, it was observed that small molecular weight aldehydes were preferred over larger aldehydes (Suloff 2002).

\section{Adsorption on Other Materials}

Aldehydes have been shown to have a high affinity towards L-cysteine. Therefore, the application of an L-cysteine-containing gel has been for proposed for the removal of AcA from indoor air. The researchers found that amongst tested amino acids (glycine, L-lysine, L-methionine, L-cysteine and L-cysteine), treating air with L-cysteine resulted in a the highest reduction of aldehyde concentration of $91 \%$ in comparison with $50-64 \%$ to water or solutions of other amino acids (Yamashita et al. 2010).

Nilvebrant et al. (Nilvebrant et al. 2001) investigated the removal of aliphatic acids, HMF, FF, phenols and ketones on an anion exchanger (AG 1-X8), which was used in its hydroxide form. When compared with other tested resins (XAD-8 and cation exchanger), AG 1-X8 showed a significantly better performance at $\mathrm{pH} 10$. The mechanism for binding of aldehydes is proposed to be hydrophobic interaction. However, when the effect on a glucose solution was tested, the anion exchanger reduced the sugar concentration by $75 \%$. Nonetheless, this effect can be counteracted by addition of inorganic ions such as sulphate (Nilvebrant et al. 2001). 
Fig. 7 Aldehyde binding by three different polymer-supported oligo(ethyleneimines); a sulfamide bond ethylenediamine; b sulfamide bond

diethylenetriamine; c sulfamide bond triethylenetetramine;

adapted from (Biçak and Șenkal 1997)
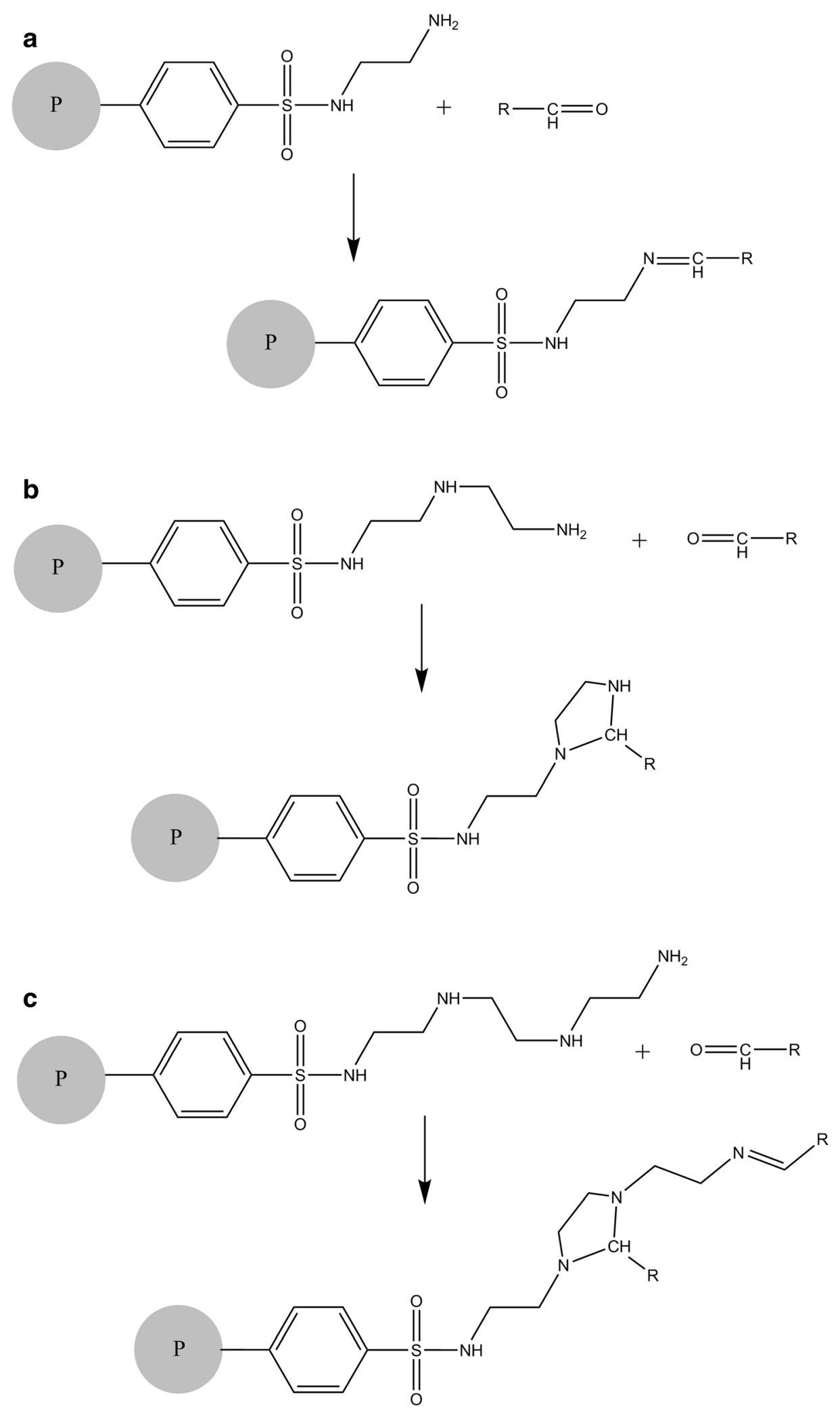

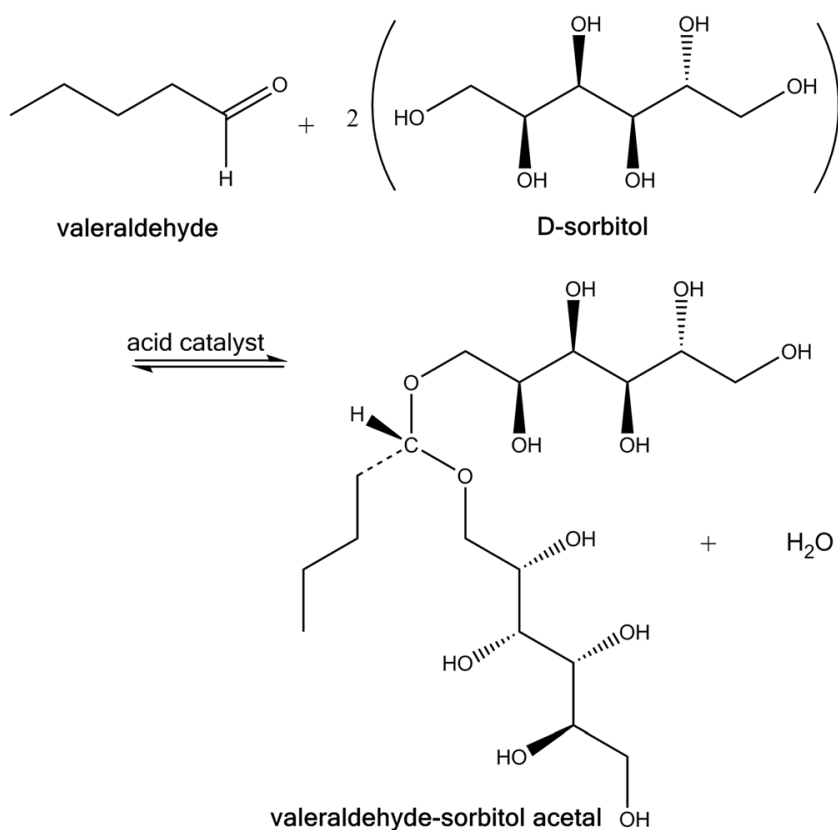

Fig. 8 Reaction of valeraldehyde with D-sorbitol to the corresponding acetal (Suloff 2002)

\section{Separation by Extraction: Supercritical Carbon Dioxide Extraction}

In a lab-scale study, the extraction of essential oil from grape bagasse for production of jam was examined (Santos et al. 2007). Temperature and fluid density can be used to modify the solubility of components in the extractant and therefore to influence the selectivity of the separation step (Schroeder et al. 1995). While there was no effect of temperature and pressure on the recovered mass of essential oil, the operating conditions influenced the composition of the essential oil. When the temperature was fixed to $303 \mathrm{~K}$ and $15 \mathrm{MPa}$, hydrocarbons were the dominated compound class in the extract. On increasing the pressure to $25 \mathrm{MPa}$ and decreasing the temperature to $290 \mathrm{~K}$, aldehydes and ketones were identified as the most important molecule class in the oil (Santos et al. 2007).

Different patents on the purification of vanillin (4-hydroxy3-methoxybenzaldehyde) were published. In US patent 4474994 A, impurities are removed from the crude vanillin, which is obtained from lignin, lignosulfonates or sulphite cooking liquor, by supercritical $\mathrm{CO}_{2}$ extraction (Makin 1984). A Chinese patent approaches the problem from a different angle by extracting vanillin from the crude mixture with supercritical $\mathrm{CO}_{2}$ (Changqing et al. 2010).

Lee et al. (Lee et al. 2008a; Lee et al. 2008b) investigated the extraction process of fish oil with supercritical carbon dioxide and off-flavour removal from fish viscera. Contrary to the above results, they found that with raising pressure and temperature, the recovered quantity was increased. It is also reported that off-flavours such as aldehydes in the remaining powder are significantly reduced after the extraction. For instance, $n$-valeraldehyde was decreased to around $9 \%$ of its initial peak area in the analysis. At a closer look however, it is found that the concentration of other aldehydes, such as isovaleraldehyde or propionaldehyde are actually elevated after the extraction (Lee et al. 2008a). Similar trends where observed by Roh et al., but they were able to nearly completely remove off-flavours from fish oil. For instance, when extracting at $30{ }^{\circ} \mathrm{C}$ and $20 \mathrm{MPa}$, butanal and pentanal were not detectable anymore, and the percentual area of propanal was reduced by $99 \%$ (Roh et al. 2006).

Supercritical $\mathrm{CO}_{2}$ extraction has also been investigated for the dealcoholisation of cider (Medina and Martínez 1997). Although aldehydes were not investigated in this publication, the authors report that flavours are extracted along with the ethanol. More specifically, aroma extraction if favoured at $40{ }^{\circ} \mathrm{C}$ and $12.5 \mathrm{MPa}$, while ethanol extraction if more favourable at $40{ }^{\circ} \mathrm{C}$ and $25.0 \mathrm{MPa}$. This may be an interesting concept to translate to aldehyde removal from AFBs.

\section{Separation by Extraction: Extractant-Impregnated Resin Technology}

A newer development is the employment of the extractantimpregnated resin technology for extraction and thus separation of aldehydes from aqueous streams. Thereby, a porous particle is functionalized by impregnating its pores with extractant as depicted in Fig. 9. The recovery of benzaldehyde from a model solution was studied by Babić et al. (Babić et al. 2006). The highest capacity was achieved with porous adsorbent Amberlite XAD-16 impregnated with Primene JM-T. Primene JM-T is a mixture of isomeric primary aliphatic amines in C18-22 range and was reported to be the most promising extract. The principle of stable formation of a Schiff base is also exploited in this case. Due to the impact on the solubility of benzaldehyde and the amines, increasing the temperature had a positive effect on the separation process (Babić et al. 2006).

A similar approach was taken by Vidal et al. (Vidal et al. 2012) by functionalizing silica materials with ionic liquids to extract organic acids, amines and aldehydes from atmospheric aerosols. In the past years, ionic liquids, which are composed of bulky non-symmetrical organic cations or different inorganic or organic anions, have gained increasing interest of researchers as a result of their negligible vapour pressure, thermal stability and tuneable viscosity and miscibility with water (Han and Row 2010). The tested ionic liquids, imidazolium, $N$-methylimidazolium and 1-alkyl-3-(propyl-3sulfonate) imidazolium showed higher extraction efficiencies for the organic acids due to the fact that anion exchange appears to be the dominant interaction, nonetheless, 
hydrophobic interaction and hydrogen bonding was also found to contribute (Vidal et al. 2012).

\section{Removal by Conversion}

Another strategy to reduce the concentration of aldehydes is to convert them to aroma neutral or positive flavour compounds. In principle the oxidation of aldehydes to the corresponding carboxylic acid or its reduction to an alcohol is possible, which can be further converted to an ester (Smit et al. 2009; Velíšek 2014). In nature for instance, alcohol dehydrogenase catalyses the reduction of 3-MB to 3-methylbutanol as the last step of the Ehrlich pathway. This is a very active reaction pathway in yeast, but the reaction is also carried out by lactic acid bacteria at a lower frequency (Arnau et al. 1998; Bradshaw et al. 1992; Chen 1977; Hatanaka et al. 1974; Schneider-Bernlöhr et al. 1981; Smit et al. 2009; Temiño et al. 2005). In turn, the conversion of 3-MB to 3-methyl butanoic acid was found to be carried out by aldehyde dehydrogenase in Staphylococcus xylosus (Beck et al. 2002; Smit et al. 2009).

In waste water treatment, the removal of odourous aldehydes from drinking water was attempted by employing the $\mathrm{UV} / \mathrm{H}_{2} \mathrm{O}_{2}$ process. Overall, a reduction in aldehyde concentration (e.g. decadienal, hexanal) and the algae-related fishy/ grassy smell could be detected by a sensory panel, however, new types of odour were produced (chalky or sweet) (Jo and Dietrich 2009). Another technique tested with waste water for the removal of aldehydes and polyphenols is electrocoagulation. Olya and Pirkarami (Olya and Pirkarami 2013) showed that a 95\% removal of aldehydes could be achieved by immersing a $\mathrm{Fe}-\mathrm{Fe}$ electrode combination into the aqueous solution. The suggested mechanism is the formation of metal hydroxides flocs during electrocoagulation and consequent adsorption of aldehyde (polymers) to the floc

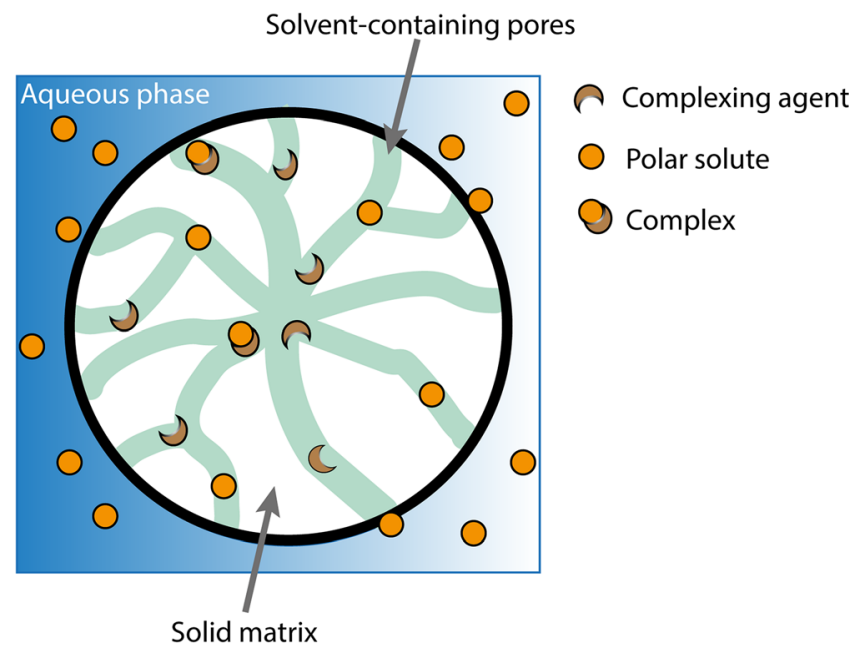

Fig. 9 Extractant-impregnated resin technology (Babić et al. 2006) surface area or direct oxidation of the organic compounds on the anode (Olya and Pirkarami 2013).

Classic organic chemistry has also identified efficient catalysts to accelerate the oxidation/reduction reactions of aldehydes. For the conversion to carboxylic acid, oxidising agents such as permanganate, bromine, oxone or copper(II) oxide are commonly employed (Haines 1988; Smith and March 2006b). Since these compounds are strong oxidising agents, they are not chemoselective and for example also convert alcohols (Tojo and Fernández 2007). Typically, the addition of organic solvents is suggested, but examples for the preparation in aqueous solution can also be found. Saadati et al. (Saadati et al. 2016) prepared a nanosized copper(II) oxide embedded in hyper-crosslinked polystyrene to catalyse the aqueous-phase oxidation of aldehydes in water. The optimum reaction conditions were observed at basic $\mathrm{pH}$ and $75{ }^{\circ} \mathrm{C}$ (Saadati et al. 2016). Another example is the oxidation of HMF to 2,5furandicarboxylic acid at high pressure conditions (40 bar) and $100{ }^{\circ} \mathrm{C}$ by active carbon functionalized with platinum and bismuth-platinum catalyst (Rass et al. 2013). The catalytic conversion is not only limited to the liquid phase. In the US Patent 7855261 B2, 'Aldehyde removal' (2010), a method for removal of a gaseous aldehyde, in particular AcA, is described for the application of removal from tobacco smoke by a filter medium. The filter support material is a polymeric composition containing acetoacetate residues and a metallic oxidising agent or oxidation catalyst (such as $\mathrm{Cu}(\mathrm{II})$ ), which oxidised contained aldehydes (Kuo et al. 2010).

The reduction of aldehydes and ketones to primary and secondary alcohols, respectively, is catalysed by complex metal hydrides such as lithium aluminium hydride or sodium borohydride. Generally, these catalysts do not reduce carbon-carbon double or triple bonds, which is advantageous when compared with other reducing agents. However, since lithium aluminium hydride readily reacts with water and alcohols these components need to be eliminated from the reaction mixture and organic solvents employed. Sodium borohydride is more chemoselective and may be used in aqueous or alcoholic solutions. Furthermore, several agents have been reported to reduce aldehydes more rapidly than ketones, amongst them are sodium triacetoxyborohydride or zinc borohydride (Smith and March 2006b). The removal of aldehydes by reduction to their alcohol is described in a patent for purification of ethylene oxide. The conversion is achieved by adding sodium or potassium borohydride according to Eq. 2. In this case, however, sodium borohydride is not chemoselective and also reacts with ketones to the adequate alcohol (Randall 1965).

$\mathrm{NaBH}_{4}+4 \mathrm{CH}_{2} \mathrm{O}+2 \mathrm{H}_{2} \mathrm{O} \stackrel{T=-10-10^{\circ} \mathrm{C}}{\longrightarrow} 4 \mathrm{CH}_{3} \mathrm{OH}+\mathrm{NaBO}_{2}$ 
Alternatively to oxidation or reduction, the reaction of glycine and L-tyrosine with $n$-heptanal has been studied to produce coloured pigments for food applications. In this way, carbonyls are removed, while simultaneously unsaturatedpolymeric pigments are formed. The experiments suggest that the formed product contains an imine linkage (Montgomery and Day 1965). The strategy of binding aldehydes in the imine form is also employed during the acidic pre-treatment step for the production of ethanol from cellulosic materials for instance, FF and HMF are formed, which are known to inhibit enzymes and microorganisms employed in the fermentation. It was shown that PEI is able to effectively remove these two inhibitory molecules from a simple aqueous solution. Interaction with contained acetic acid was reported to be avoidable by addition of chloride, sulphate or hydroxide ions. The aldehydes could mostly be desorbed from the resin by applying a dilute sulphuric acid solution (Carter et al. 2011).

Also, bisulphite is known to form adducts with aldehydes, methyl ketones, cyclic ketones, $\alpha$-keto esters and isocyanates, as shown in Fig 10. The addition products are readily soluble in water and the reaction is reversible through addition of either acid or base. Formation of addition products is not observed for most ketones, presumably due to steric hindrance (Smith and March 2006a).

This mechanism finds application for the elimination of aldehyde impurities from organic liquids, which are passed through a bed of solid sodium bisulphite particles. The bed can be regenerated by heating to $75-120^{\circ} \mathrm{C}$. Due to the high solubility of sodium bisulphite $\left(420 \mathrm{~g} \mathrm{~L}^{-1}\right)$ and its addition product, this system is only applicable to liquids with a water content of less than 10\% (Mameniskis and Washall 1974). Another way of addressing the separation problem was proposed by Boucher et al. (Boucher et al. 2017). In their work, a liquid-liquid extraction process was developed, where aldehydes were allowed to react with bisulphite in a watermiscible solvent and then separated from the substrate by addition of a water-immiscible organic solvent (Boucher et al. 2017).

\section{Removal by Pervaporation}

In food industry, pervaporation has gained attention to separate and concentrate flavour compounds (Saffarionpour and Ottens 2018). An example of applying this technique is the concentration of key flavours of soluble coffee by pervaporation. Weschenfelder et al. investigated the impact of feed flow rate, temperature and permeate pressure on the process performance. While they were able to separate and concentrate flavour compounds from the industrial solution, optimisation is required to achieve the desired aroma profile in the product (Weschenfelder et al. 2015). An earlier study performed in 2005 successfully recovered key flavour compounds from apple essence, orange aroma and black tea distillate, both, in batch and continuous pervaporation operation. However, the authors state that a significant loss of aromas was observed due to evaporation leakage (She and Hwang 2006). Another work focusses on the recovery of pomegranate aroma compounds (e.g. 3-MB) from a model solution. All studied flavours were concentrated. Coupling effects between them were observed that indicate an increased effect at higher aroma concentrations (Raisi and Aroujalian 2011). Nonetheless, quantitative studies are required to understand and describe the coupling phenomena.

\section{Aldehyde Removal-State of the Art in Brewing}

\section{Reduction of Aldehydes During Cold Contact Fermentations}

The principle of producing alcohol-free or low-alcoholic beer via a biological route is to prevent the formation of ethanol during the fermentation step through inhibiting yeast's metabolism. This is achieved by short contact times of the wort with the microorganism at low temperatures of around $2{ }^{\circ} \mathrm{C}$. Therefore, this process is often referred to as 'cold contact fermentation' (CCF) or 'cold contact process' Despite the low activity of yeast, ester and fusel alcohol production as well as carbonyl reduction can be observed (Narziss et al. 1991). The effect heat-deactivated yeast cells at $0{ }^{\circ} \mathrm{C}$ on the aldehyde concentration in wort was studied by Perpète and Collin (Perpète and Collin 1999a) and compared with to the concentration profile of a fermentation with viable yeast at the same conditions (Perpète and Collin 1999b). Although an effect of the heat-deactivated yeast on the aldehyde profile is observed, the concentration level decreases only by $10-30 \%$. In contrast, hexanal, as a linear aldehyde, is nearly depleted in the presence of active yeast. Yet, the reduction of the branched Strecker aldehyde, 3-MB, is limited to a maximum of 60-70\% of the initial aldehyde concentration found in the raw material. Both, chemical binding and enzymatic reduction are more distinct for linear aldehydes than for branched molecules (Perpète and Collin 1999b).

Limitations in yeast activity and vitality were initially suspected to be responsible for the restricted reduction of branched Strecker aldehydes. This was, however, disproven during experiments with partially fermented wort. The evolution of 2-MB and 3-MB during CCF was measured. After the initial reduction of the concentration to around $30-40 \%$ of the initial concentration, the fermenter was pitched with 2- and 3$\mathrm{MB}$, respectively. The yeast was yet again able to reduce the added aldehydes within $5 \mathrm{~h}$ to the characteristic threshold. Therefore, it is concluded by the authors that the physiological state of the yeast cells cannot be the reason for the insufficient reduction in Strecker aldehydes. To confirm this hypothesis, a second experiment was performed, where the partially fermented wort was pitched with freshly propagated yeast 


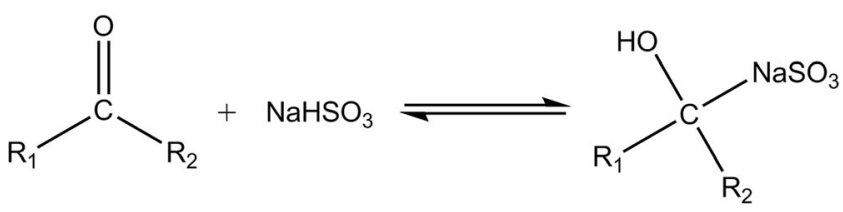

Fig. 10 Reaction of bisulphate with aldehydes and ketones

after $5 \mathrm{~h}$. Once more, the same residual concentration was reached. Although the authors conclude that an active yeast is required for Strecker aldehyde reduction, they do not distinguish between intact, but metabolic inactive cell, and viable yeast cells. Heat deactivation most likely leads to disruption or alteration of the cell structure. It therefore remains unclear, if the observed decrease in aldehyde concentration is due to enzymatic or adsorptive reduction.

Nevertheless, these findings could also suggest that aldehyde interaction with wort components might be the reason for the limited degradation of worty off-flavours (Perpète and Collin 2000b). As suggested elsewhere, involved components for aldehyde binding are cysteine and sulphite (Baert et al. 2015a; Baert et al. 2015b).

The hypothesis that sulphite readily binds to aldehydes and interferes in the aldehyde reduction during CCF was experimentally investigated. On adding $10 \mathrm{ppm}$ sulphite to the wort during the fermentation, the reduction of 3-MB and methional was significantly inhibited. However, the concentration of 2MB was again decreased to its characteristic mark. This difference had not been observed during the fermentation studies. Furthermore, the sulphite concentration during the original fermentation was only at ppb level. Hence, the authors of this work conclude that other wort compounds must be responsible for the binding of aldehydes during CCF (Perpète and Collin 2000b). From the study of wine polyphenols, it is known that interactions with aroma substances occur (Dufour and Bayonove 1999). As polyphenolic compounds also occur in wort, they might be involved in the binding of wort aldehydes. The theory was tested by adding $100 \mathrm{ppm}$ catechin to a $\mathrm{CCF}$ of $12^{\circ} \mathrm{P}$ wort. For $3-\mathrm{MB}$, a clear trend could be observed that is less aldehyde were converted enzymatically, while the trend for 2-MB was less pronounced. The statistical relevance could however be confirmed by a Student's $t$ test. The authors hence conclude an involvement of polyphenols in the inhibited aldehyde removal by yeast (Perpète and Collin 2000b).

On a closer look, it becomes apparent that yeast is even able to produce aldehydes, such as 3-MB, in the later stage of the CCF. An experiment of Perpète and Collin (2000) with deuterated leucine, a precursor for 3-MB formation, provides evidence that yeast is able to synthesise the aldehyde at such low temperatures. It must be noted, however, that the rate of formation of 3-MB increases over time and a minimum aldehyde concentration can be identified for each process.
Therefore, close monitoring of the CCF to avoid elevated aldehyde levels is a key factor (Perpète and Collin 2000a).

Newer developments in this field aim at increasing the formation of positive flavours or masking molecules in AFBs. A special Saccharomyces cerevisiae strain producing increased concentration of organic acids such as lactate and citrate could help to mask the wort flavour features of AFBs (Selecký et al. 2008). In a study of two 5,5,5-trifluoro-DLleucine-resistant Saccharomyces pastorianus strains, spontaneous mutants were able to produce higher levels of isoamyl alcohol and isoamyl acetate when compared with the parental strain. However, levels were still lower than in regular beer and the product had to be diluted to achieve the legally allowed threshold of 0.5 vol.\% (Strejc et al. 2013).

\section{Reduction of Aldehydes During Continuous Fermentations of AFBs}

Similar to the CCF process immobilised yeast strains are cultivated in specialised reactors under stress conditions, which limit the cell metabolism. Under these conditions, only a fraction of the contained sugars is metabolised, resulting in low ethanol concentrations $(<0.08 \%)$. In the absence of oxygen, the redox balance is impacted, which enhances reduction of wort aldehydes and intracellular metabolites thus the formation of esters and higher alcohols (van Iersel et al. 1995). Depending on the fermentation parameters (aeration, residence time, temperature) and the selected yeast strain, the product specification can be controlled with respect to ethanol concentration, amount of esters and the ratio of higher alcohols to esters formed. The difficulty lies in achieving the correct balance of sensory compounds in the short time. Higher concentrations of diacetyl and aldehydes have been observed, while ester concentrations remain relatively low (Lehnert 2009). During the fermentation, van Iersel et al. (Van Iersel et al. 2000) found that immobilising yeast on DEAE-cellulose improves the reducing capacity during the production of AFB. On varying the oxygen transfer rate of a continuous fermentation process it was found that with decreasing oxygen transfer rate, the reduction efficiency of aldehydes could be increased. The reduction in 3-MB was as high as $92 \%$ and near to $100 \%$ for unbranched aldehydes such as hexanal at an oxygen transfer rate of $1 \mathrm{mg} \mathrm{L}^{-1} \mathrm{~h}^{-1}$. It should be however mentioned that the ethanol concentration was with $0.5 \mathrm{vol} . \%$ well above the more conservative definition of an AFB (Lehnert et al. 2008).

\section{Reduction of Perceived Wort Flavour by Masking Components}

Literature suggests that besides the enzymatic reduction through yeast, other biomolecules play a role in the removal of aldehydes from wort. A study of Perpète (1999) showed 
aldehyde concentrations can be reduced by $20-95 \%$ if amino acids or industrial wort proteins are added to a model solution. The authors observed that the majority of the chemical binding occurs within the first $30 \mathrm{~min}$ of the experiment. Presumably, the aldehydes are still contained in the medium, but in a chemically bound form, which is not measured with the analytical method employed. The fact that an increasing temperature decreases the concentration of aldehydes measured in the medium suggests furthermore that the formed chemical bond is based on an endothermic reaction (Perpète and Collin 1999b). The impact on other beer constituents was not included in the study and therefore the selectivity for aldehydes is in question.

A similar approach was applied in US patent 280399A1, where the wort flavour of a 'beer-like malt beverage' is reduced by adding a terpene (terpinolene) to wort. The authors describe that addition of 0.05-5 ppm terpinolene reduced the perceived strength of wort flavour and improved the overall aroma balance of the product. It should be noted, however, that the methodology of the sensory evaluation is not further specified in the patent and the actual concentration or volatility in key wort flavour compounds was not analysed (Murakami et al. 2013).

\section{Aldehyde Removal During Dealcoholisation}

Despite their mostly high volatility, aldehydes are also found in thermally dealcoholized products. Due to the heat impact heat indicators such as FF are simultaneously formed and evaporated. Generally, the final concentration of aldehydes is lower in fresh AFBs compared with their alcoholic starting beer, but on increasing the operating temperature to $42-48^{\circ} \mathrm{C}$, a slight rise in 2-furfural concentration is observed. Processes, where lost flavours are recovered from alcoholic condensates and added back to the AFB have been reported a twofold concentration of 2-furfural and $\gamma$-nonalacton (Müller et al. 2016).

Fig. 11 Aldehyde concentrations in different AFBs compared with average concentration in lagers adapted from Andrés-Iglesias et al. (Andrés-Iglesias et al. 2016). a Spanish beer ( 0.01 vol.\%), dealcoholized by vacuum distillation; b Czech beer ( 0.49 vol.\%), dealcoholized by vacuum distillation; c Czech beer $(0.49$ vol.\%) produced by special yeast strain; d Czech beer (0.50 vol.\%) produced by $\mathrm{CCF}$
A vast study of aldehyde profiles in Czech and Spanish lager beers was performed by Andrés-Inglesias et al. (2016). Twenty-eight beers, including four AFBs were analysed for defined aldehydes and ketones. The results are depicted in Fig. 11. Generally, concentrations of aldehydes and ketones are lower, however for some compounds close or in case of trans-non-2-enal above their respective flavour threshold (Andrés-Iglesias et al. 2016). This is particularly true, when the matrix effect explained in 'Impact of Alcohol-Free Beer Composition on the Perception of Wort Off-Flavours' is taken into account. Nonetheless, as the study did not include sensory panels, it is difficult to conclude the perception of off-flavours in the tested AFBs. When comparing AFBs produced by vacuum distillation (see Fig. 11, beer a and b), with biologically produced AFBs (see Fig. 11, beer c and d) it is conspicuous that cold contacted fermented beer shows the highest concentration for all compounds, except for diacetyl. Methional, which has a lower vapour pressure and flavour threshold, was not measured although it is the predominant wort flavour in AFBs.

\section{Development in Membrane-Based Technologies}

Newer developments can be discovered in the field on membrane-based separations. Catarino and Mendes (Catarino and Mendes 2011) propose to separate flavours selectively from the beer stream by pervaporation before dealcoholisation by stripping (spinning cone column). This exhibits the advantage that flavours are collected in a stream with a lower ethanol concentration and can be dosed back to the alcohol-free end-product. In the study it is found that AcA can be removed together with esters and higher alcohols prior to entering the stripping equipment (Catarino and Mendes 2011). Nonetheless, this process set-up is disadvantageous for aldehyde removal due to the fact that the separation is non-selective and that molecules will be re-formed during the dealcoholisation step. Another approach was followed by Liguori et al. (Liguori et al. 2015). In their work, modified

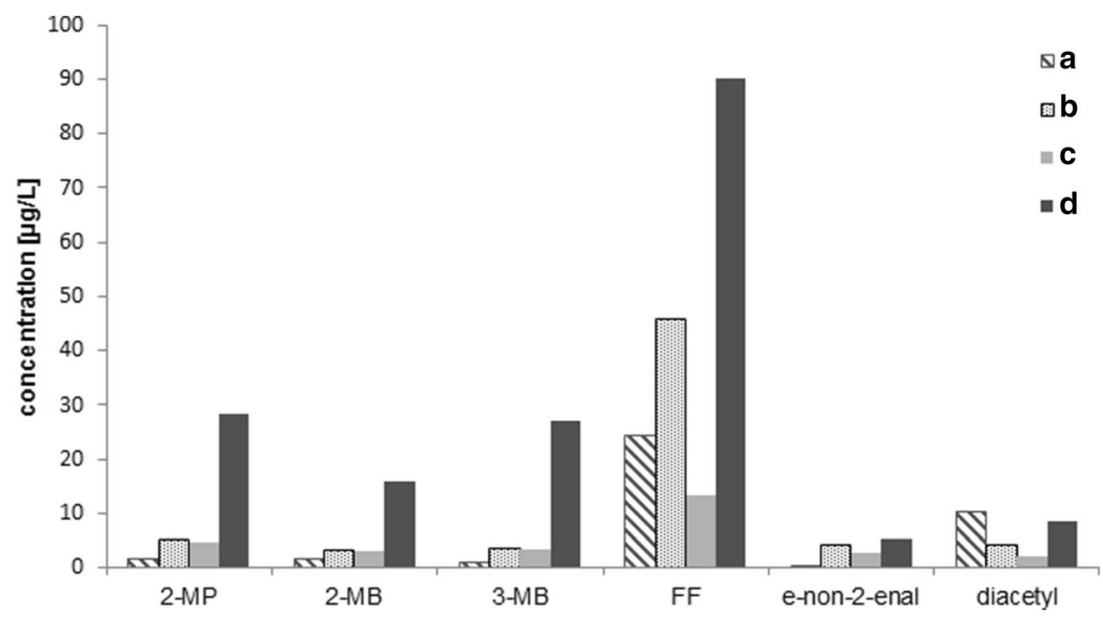


osmotic distillation was employed to dealcoholize beer to an ethanol content $<0.5$ vol. $\%$. The total aldehyde content was decreased from 57.24 to $3.82 \mathrm{mg} \mathrm{L}^{-1}$ and in particular, 2-MB, 3 -MB and Met were reduced by 85, 94 and nearly $100 \%$, respectively, although the process was not selective for aldehydes only.

\section{Removal Through Adsorptive Technologies}

The idea of reducing the wort flavour with adsorptive techniques has been described in several patents (Shimizu and Takashio 2003; Takura et al. 2012). In US 2012/0207909, $\mathrm{AC}$ is used for batch uptake tests at low temperatures to remove aldehydes. They found that using an amount of 10$30 \mathrm{~g}_{\mathrm{AC}} \mathrm{kg}^{-1}$ of malt grist is optimal to reduce the wort flavour; if the ratio of $\mathrm{AC}$ to wort is increased, this results in an overall decrease in flavour and thus in an insufficient beer taste. Chemical analysis of a production scale batch test at a phase ratio of $18.4 \mathrm{~g}_{\mathrm{AC}} \mathrm{kg}_{\mathrm{wort}}{ }^{-1}$ showed a reduction of 2-MB from 10.2 to $6.4 \mu \mathrm{g} \mathrm{L}^{-1}, 3-\mathrm{MB}$ from 29.6 to 20.2 and methional from 19.2 to $10.1 \mu \mathrm{g} \mathrm{L}^{-1}$. A higher removal could be achieved by using a higher phase ratio or a different type of AC (Takura et al. 2012). Another approach was taken in US 2012/0207909, where ion-exchange and synthetic resins were studied for reducing the 'rough' flavour in alcoholic malt drinks. Both, ion-exchange and synthetic resins (XAD7, XAD4) proved to reduce typical wort flavours in alcoholic beers, even after storing the beer at $30^{\circ} \mathrm{C}$ for 1 month. The process is, however, not selective for aldehyde removal, but during the treatment, other molecules such as Maillard components, organic acids and polyphenols are also removed (Shimizu and Takashio 2003).

\section{Methods Employed for Formation Inhibition in Regular Beer}

The formation of Strecker aldehydes during the storage of regular beer is a commonly recognised issue. Besides reducing the oxygen level in the bottled product, several other methods have been developed to reduce or inhibit the formation of wort flavour during storage. As such enzymes, i.e. aldose reductase have been patented to metabolise 3deoxyglucosone, which is involved in the Strecker degradation. By converting the precursor, aldehyde formation is circumvented (Bravo et al. 2002). As it is known, that the main factor contributing to staling are the malt quality and the brewing process itself (De Clippeleer et al. 2010), another approach was taken by Yano et al. (Yano et al. 2008). In this study, the effect of treating a part of the wort (second wort, > $10 \%$ ) during and before the wort boiling process with adsorbents (AC, bentonite, silica gel and PVPP) was investigated. Beers treated with $\mathrm{AC}$ resulted in a product with an improved organoleptic taste stability, i.e. a reduced the oxidized flavour of forced aged beer compared with a reference brew.
However, since the chemical analysis of the fresh beer showed only a reduction in $\gamma$-nonanlacton concentration and other components such as Strecker aldehydes were unaffected, it was postulated that this difference is not related to a direct wort flavour removal, but rather, the reduction of precursors (Yano et al. 2008).

\section{Conclusion and Outlook}

Aldehyde removal has been a subject of interest for different applications in the past. Due to the limitations of creating a pure product and following traditional approaches and also obeying to general regulations of food administration, the process development for selective off-flavour removal from AFB has been restricted so far. At this point, applied technologies are either not selective or effective enough to efficiently separate aldehydes from the beer stream. The motivation of creating a healthy and safe beverage alternative that meets the customer's expectation is, however, a key driver for the upcoming market. The aim of such an improvement should be the development of a novel process design that is able to engineer the desired flavour profile to the beer matrix while preserving the product quality.

In this work, the chemistry of beer aldehydes with regard to alcohol-free beverages and aldehyde separation processes from industry and research have been compiled. Since aldehyde removal is a focus of interest in many fields and industries, such as biotechnology, packaging or air purification, researcher can benefit from the vast level of knowledge and data available from all disciplines. While not all process concepts presented can be applied for the case of AFB production, many promising technologies are found in literature. Amongst these, adsorptive removal is identified as the most suitable method to specifically target worty off-flavours from aqueous food streams. With regard to the selectivity, the use of hydrophobic resins or amino-modified polystyrenes should be investigated in order to discover the complex interaction of aldehydes, beer matrix components and adsorbents. Going one step further, other materials may be considered such as natural polymers or inorganic adsorbents that have not been investigated for this application, yet.

Reducing sugars, hop acids, hydrophobic flavour components, vitamins, polyphenols and small organic molecules may potentially interfere in the process, thus, it is required to define the product specifications and acceptable losses of nutrients to the separation medium. It is for instance known, that amines and amides as functional aldehyde scavenger also react with organic acids, thus resulting in a reduced selectivity for targeted compounds (Speer et al. 1999). Consequently, suitable reaction conditions should be created, which enable a more selective removal of off-flavours. In this approach, a smart process design to circumvent bottlenecks is of uttermost 
importance. The combination of biological methods for AFB production with a downstream off-flavour removal unit is one possibility to explore. Potentially, an integrated process of adsorption and physical dealcoholisation depicts an attractive opportunity for quality improvement of AFBs. Future research should furthermore consider the impact of other flavour groups to identify specifically problematic compounds with regard to the perception of alcohol-free beverages.

Funding Information The authors would like to thank Heineken Supply Chain B.V. for funding this project.

Open Access This article is distributed under the terms of the Creative Commons Attribution 4.0 International License (http:// creativecommons.org/licenses/by/4.0/), which permits unrestricted use, distribution, and reproduction in any medium, provided you give appropriate credit to the original author(s) and the source, provide a link to the Creative Commons license, and indicate if changes were made.

\section{References}

Aimoto, U., Kobayashi, T., \& Adach, S. (2011). Temperature dependence of retention factor of saccharides on hydrophobic resin. Japan. Journal of Food Engineering, 12, 165-168. https://doi.org/10. $11301 /$ jsfe. 12.165 .

Al-Malaika, S. (2000). Thermoplastic moulding compositions and polymer additives (WO2000066659 A1). Prescot: Colormatrix Europe Ltd..

Andrés-Iglesias, C., Nešpor, J., Karabín, M., Montero, O., Blanco, C. A., \& Dostálek, P. (2016). Comparison of carbonyl profiles from Czech and Spanish lagers: traditional and modern technology. LWT - Food Science and Technology, 66, 390-397. https://doi.org/10.1016/j.lwt. 2015.10.066.

Arnau, J., Jørgensen, F., Madsen, S. M., Vrang, A., \& Israelsen, H. (1998). Cloning of the Lactococcus lactis adhE gene, encoding a multifunctional alcohol dehydrogenase, by complementation of a fermentative mutant of Escherichia coli. Journal of Bacteriology, 180, 3049-3055.

Babić, K., van der Ham, L., \& de Haan, A. (2006). Recovery of benzaldehyde from aqueous streams using extractant impregnated resins. Reactive and Functional Polymers, 66, 1494-1505. https://doi.org/ 10.1016/j.reactfunctpolym.2006.04.013.

Baert, J. J., De Clippeleer, J., Hughes, P. S., De Cooman, L., \& Aerts, G. (2012). On the origin of free and bound staling aldehydes in beer. Journal of Agricultural and Food Chemistry, 60(46), 11449-11472. https://doi.org/10.1021/jf303670z.

Baert, J. J., De Clippeleer, J., De Cooman, L., \& Aerts, G. (2015a). Exploring the binding behavior of beer staling aldehydes in model systems. Journal of the American Society of Brewing Chemists, 73, 100-108. https://doi.org/10.1094/ASBCJ-2015-0109-01.

Baert, J. J., De Clippeleer, J., Jaskula-Goiris, B., Van Opstaele, F., De Rouck, G., Aerts, G., \& De Cooman, L. (2015b). Further elucidation of beer flavor instability: the potential role of cysteine-bound aldehydes. Journal of the American Society of Brewing Chemists, 73, 243-252. https://doi.org/10.1094/ASBCJ-2015-0531-01.

Beal, A. D., \& Mottram, D. S. (1994). Compounds contributing to the characteristic aroma of malted barley. Journal of Agricultural and Food Chemistry, 42, 2880-2884. https://doi.org/10.1021/ jf00048a043.
Beck, H. C., Hansen, A. M., \& Lauritsen, F. R. (2002). Metabolite production and kinetics of branched-chain aldehyde oxidation in Staphylococcus xylosus. Enzyme and Microbial Technology, 31, 94-101. https://doi.org/10.1016/S0141-0229(02)00067-4.

Biçak, N., \& Șenkal, B. F. (1997). Aldehyde separation by polymersupported oligo(ethyleneimines). Journal of Polymer Science Part A: Polymer Chemistry, 35, 2857-2864. https://doi.org/10.1002/ (SICI)1099-0518(199710)35:14<2857::AID-POLA6>3.0.CO;2-N.

Biçak, N., Soydan, A. B., Șenkal, B. F., Koza, G., \& Yener, M. (1997). 1, 2-Diaminoethane-containing epoxy resins for separation of aldehydes. Reactive and Functional Polymers, 39, 197-205. https:// doi.org/10.1016/S1381-5148(98)00010-8.

Blanco, C. A., Andrés-Iglesias, C., \& Montero, O. (2016). Low-alcohol beers: flavor compounds, defects, and improvement strategies. Critical Reviews in Food Science and Nutrition, 56(8), 1379 1388. https://doi.org/10.1080/10408398.2012.733979.

Boucher, M. M., Furigay, M. H., Quach, P. K., \& Brindle, C. S. (2017). Liquid-liquid extraction protocol for the removal of aldehydes and highly reactive ketones from mixtures. Organic Process Research \& Development, 21, 1394-1403. https://doi.org/10.1021/acs.oprd. $7 \mathrm{~b} 00231$.

Boulton, C. (2013). Encyclopaedia of Brewing. Hoboken: Wiley.

Bradshaw, C. W., Hummel, W., \& Wong, C. H. (1992). Lactobacillus kefir alcohol dehydrogenase: a useful catalyst for synthesis. Journal of Organic Chemistry, 57, 1532-1536.

Brányik, T., Silva, D. P., Baszczyňski, M., Lehnert, R., \& Almeida e Silva, J. B. (2012). A review of methods of low alcohol and alcohol-free beer production. Journal of Food Engineering, 108, 493-506. https://doi.org/10.1016/j.jfoodeng.2011.09.020.

Bravo A, Beatriz S, Rangel-Aldao Rafael (2002) EP0773285B1: method for producing an alcohol-containing fermented malt beverage with stabilized flavour.

Bravo, A., Herrera, J. C., Scherer, E., Ju-Nam, Y., Rübsam, H., Madrid, J., Zufall, C., \& Rangel-Aldao, R. (2008). Formation of $\alpha$-dicarbonyl compounds in beer during storage of pilsner. Journal of Agricultural and Food Chemistry, 56, 4134-4144. https://doi.org/10.1021/ jf703696p.

Briggs, D. E., Boulton, C. A., Brookes, P. A., \& Stevens, R. (2004). Brewing-science and practice. Sawston: Woodhead Publishing.

Brodie, V.,\& Visioli, D.L. (1995). Aldehyde scavenging compositions and methods relating thereto. United States patent No. US5413827 A. E. I. Du Pont De Nemours and Company

Canteli, A. M. D., Carpiné, D., Scheer, A. P., Mafra, M. R., \& IgarashiMafra, L. (2014). Fixed-bed column adsorption of the coffee aroma compound benzaldehyde from aqueous solution onto granular activated carbon from coconut husk. LWT - Food Science and Technology, 59, 1025-1032. https://doi.org/10.1016/j.lwt.2014.06. 015.

Carabasa-Giribet, M., \& Ibarz-Ribas, A. (2000). Kinetics of colour development in aqueous glucose systems at high temperatures. Journal of Food Engineering, 44, 181-189. https://doi.org/10. 1016/S0260-8774(00)00027-3.

Carey, F. A., \& Sundberg, R. J. (2007). Addition, condensation and substitution reactions of carbonyl compounds. In Advanced organic chemistry: Part A: structure and mechanisms (pp. 629-711). Boston: Springer US. https://doi.org/10.1007/978-0-387-44899-2 7.

Carter, B., Gilcrease, P. C., \& Menkhaus, T. J. (2011). Removal and recovery of furfural, 5-hydroxymethylfurfural, and acetic acid from aqueous solutions using a soluble polyelectrolyte. Biotechnology and Bioengineering, 108, 2046-2052. https://doi.org/10.1002/bit. 23153.

Catarino, M., \& Mendes, A. (2011). Non-alcoholic beer-a new industrial process. Separation and Purification Technology, 79, 342-351. https://doi.org/10.1016/j.seppur.2011.03.020. 
Catarino, M., Ferreira, A., \& Mendes, A. (2009). Study and optimization of aroma recovery from beer by pervaporation. Journal of Membrane Science, 341, 51-59. https://doi.org/10.1016/j.memsci. 2009.05.038.

Chambers Iv, E., \& Koppel, K. (2013). Associations of volatile compounds with sensory aroma and flavor: The complex nature of flavor. Molecules, 18(5), 4887-4905. https://doi.org/10.3390/ molecules 18054887.

Changqing, L., Chen, C., Yu, L.G., W.; Xiang, Z., Yaoxian, L., Yongxiang, W. (2010). Carbon dioxide supercritical extraction method for vanillic aldehyde or ethyl vanillin raw product. China Patent

Chen, E. C. H. (1977). Keto acid decarboxylase and alcohol dehydrogenase activities of yeast in relation to the formation of fusel alcohols. Canadian Institute of Food Science and Technology Journal, 10, 27-30.

Ching, T.Y., Goodrich, J.L., Katsumoto, K. (2000). Oxygen scavenging system including a by-product neutralizing material. United States pattern No. CA2247985 C.

Chuyen, N.V. (1998) Maillard reaction and food processing. In: Processinduced chemical changes in process-induced chemical changes in food, 213-235. https://doi.org/10.1007/978-1-4899-1925-0 18

Conner, J. M., Birkmyre, L., Paterson, A., \& Piggott, J. R. (1998). Headspace concentrations of ethyl esters at different alcoholic strengths. Journal of the Science of Food and Agriculture, 77, 121-126. https://doi.org/10.1002/(SICI)1097-0010(199805)77: $1<121::$ AID-JSFA14>3.0.CO;2-V.

Contreras-Calderón, J., Guerra-Hernández, E., \& García-Villanova, B. (2008). Indicators of non-enzymatic browning in the evaluation of heat damage of ingredient proteins used in manufactured infant formulas. European Food Research and Technology, 227, 117-124. https://doi.org/10.1007/s00217-007-0700-2.

De Clippeleer, J., De Rouck, G., De Cooman, L., \& Aerts, G. (2010). Influence of the hopping technology on the storage-induced appearance of staling aldehydes in beer. Journal of the Institute of Brewing, 116, 381-398. https://doi.org/10.1002/j.2050-0416.2010.tb00789.x.

de Jongh J, Peters W, vanTeeffelen C (2014) Ruigrok Net Panel. Amsterdam

de Oliveira, A. V. B., Kartnaller, V., Pedrosa, M. S. P., \& Cajaiba, J. (2015). Production of a low-cost scavenger resin to capture aldehydes and ketones in solutions. Journal of Applied Polymer Science, 132. https://doi.org/10.1002/app.42291.

De Schutter, D. P., Saison, D., Delvaux, F., Derdelinckx, G., Rock, J.-M., Neven, H., \& Delvaux, F. R. (2008). Release and evaporation of volatiles during boiling of unhopped wort. Journal of Agricultural and Food Chemistry, 56(13), 5172-5180. https://doi.org/10.1021/ jf800610x.

Delgado, R. M., Zamora, R., \& Hidalgo, F. J. (2015). Contribution of phenolic compounds to food flavors: Strecker-type degradation of amines and amino acids produced by o- and p-diphenols. Journal of Agricultural and Food Chemistry, 63(1), 312-318. https://doi.org/ 10.1021/jf5047317.

DelNobile MA, Buonocore GG, sFava P, Piergiovanni L (2002) Modeling of hexanal sorption kinetic in an aldehydes scavenger film intended for food packaging applications. Journal of Food Science 67:2687-2691. doi:https://doi.org/10.1111/j.1365-2621.2002. tb08799.x

Drese, J. H., Talley, A. D., \& Jones, C. W. (2011). Aminosilica materials as adsorbents for the selective removal of aldehydes and ketones from simulated bio-oil. ChemSusChem, 4(3), 379-385. https://doi. org/10.1002/cssc.201000347.

Dufour, C., \& Bayonove, C. L. (1999). Interactions between wine polyphenols and aroma substances. An insight at the molecular level. Journal of Agricultural and Food Chemistry, 47(2), 678-684. https://oi.org/10.1021/jf980314u.
Emerson, D. W., Emerson, R. R., Joshi, S. C., Sorensen, E. M., \& Turek, J. E. (1979). Polymer-bound sulfonylhydrazine functionality. Preparation, characterization, and reactions of copoly(styrenedivinylbenzenesulfonylhydrazine). The Journal of Organic Chemistry, 44, 4634-4640. https://doi.org/10.1021/jo00393a036.

Ewlad-Ahmed, A. M., Morris, M. A., Patwardhan, S. V., \& Gibson, L. T. (2012). Removal of formaldehyde from air using functionalized silica supports. Environmental Science \& Technology, 46(24), 13354-13360. https://doi.org/10.1021/es303886q.

FDA. (2002). GRAS Notices. Accessed 13 Mar 2017

Gesser, H.D. (1985). Abatement of indoor pollutants. United States patent No. US4547350 A.

Gesser, H.D. (1990) Removal of aldehydes and acidic gases from indoor air. United States patent No. US4892719 A.

Gesser, H. D., \& Fu, S. (1990). Removal of aldehydes and acidic pollutants from indoor air. Environmental Science \& Technology, 24, 495497. https://doi.org/10.1021/es00074a005.

Haines, A. H. (1988). Oxidation of carbonyl compounds, methods for oxidation of Organic Compounds (pp. 241-275). Academic Press. https://doi.org/10.1016/B978-0-12-315502-3.50011-X.

Han, D., \& Row, K. H. (2010). Recent applications of ionic liquids in separation technology. Molecules, 15(4), 2405-2426. https://doi. org/10.3390/molecules15042405.

Harrison, H. R., Mundy, A. P., Buckee, G. K., Fogg, M., Kennedy, R., \& Byrne, J. (1998). Collaborative determination of the $\mathrm{pH}$ of beer and wort. Journal of the Institute of Brewing, 104, 123-126.

Hatanaka, A., Kajiwara, T., \& Tomohiro, S. (1974). Purification and properties of alcohol dehydrogenase from Leuconostoc mesenteroides. Agricultural and Biological Chemistry, 38, 18191833. https://doi.org/10.1080/00021369.1974.10861429.

Hertel, M. (2011). Verfahren zur Dealkoholisierung von Getränken und zugehörige Vorrichtung (DE112010000824 A5).

Hidalgo, F. J., \& Zamora, R. (2004). Strecker-type degradation produced by the lipid oxidation products 4,5-epoxy-2-alkenals. Journal of Agricultural and Food Chemistry, 52(23), 7126-7131. https://doi. org/10.1021/jf048883r.

Hidalgo, F. J., \& Zamora, R. (2016). Amino acid degradations produced by lipid oxidation products. Critical Reviews in Food Science and Nutrition, 56(8), 1242-1252. https://doi.org/10.1080/10408398. 2012.761173.

Hidalgo, F. J., Delgado, R. M., \& Zamora, R. (2013). Intermediate role of $\alpha$-keto acids in the formation of Strecker aldehydes. Food Chemistry, 141, 1140-1146. https://doi.org/10.1016/j.foodchem. 2013.03.068.

Hodge, J. E. (1955). The amadori rearrangement advances in carbohydrate chemistry, 10, 169-205. https://doi.org/10.1016/S00965332(08)60392-6.

Hodge, J. E., \& Rist, C. E. (1953). The Amadori rearrangement under new conditions and its significance for non-enzymatic browning reactions. Journal of the American Chemical Society, 75, 316-322.

Howell, E., Ponasik, J.A. (2008). Acetaldehyde scavenging by addition of active scavengers to bottle closures. United States patent No. US20070020418 A1.

Huang, Y., Tippmann, J., \& Becker, T. (2017). Kinetic studies of main wort flavor compounds and iso- $\alpha$-acids during wort boiling: a review. European Food Research and Technology, 243(9), 14851495. https://doi.org/10.1007/s00217-017-2858-6.

Jeřábek, K., Hanková, L., \& Prokop, Z. (1994). Post-crosslinked polymer adsorbents and their properties for separation of furfural from aqueous solutions. Reactive Polymers, 23, 107-112. https://doi.org/10. 1016/0923-1137(94)90008-6.

Jo, C. H., \& Dietrich, A. M. (2009). Removal and transformation of odorous aldehydes by UV/H2O2. Journal of Water Supply: Research and Technology-AQUA, 58, 580-586. https://doi.org/10. 2166/aqua.2009.121. 
Jung, D.-M., de Ropp, J. S., \& Ebeler, S. E. (2000). Study of interactions between food phenolics and aromatic flavors using one- and twodimensional 1H NMR spectroscopy. Journal of Agricultural and Food Chemistry, 48(2), 407-412. https://doi.org/10.1021/ jf9906883.

Karlsson, H. O. E., \& Trägårdh, G. (1997). Aroma recovery during beverage processing. Journal of Food Engineering, 34, 159-178. https://doi.org/10.1016/S0260-8774(97)00081-2.

Koller, K.B., Wrenn, S.E., Houck, W.G., Paine, J.P. (1999) Filter for selective removal of gaseous component (WO2000025610A1)

Kroh, L. W. (1994). Caramelisation in food and beverages. Food Chemistry, 51, 373-379. https://doi.org/10.1016/0308-8146(94) 90188-0.

Kuo, T., Vineyard, M.K., Liang, W.C. (2010). Aldehyde removal. United States patent No. US7855261 B2.

Lee, M. K., Uddin, M. S., \& Chun, B. S. (2008a). Off-flavors removal and storage improvement of mackerel viscera by supercritical carbon dioxide extraction. Journal of Environmental Biology, 29(4), 591-597.

Lee, Y. G., Oh, C., Kim, D. W., Jun, Y. D., \& Oh, S. G. (2008b). Preparation of composite silica particles for the removal of formaldehyde at room temperature. Journal of Ceramic Processing Research, 9, 302-306.

Lehnert, R. (2009). Optimization of lab-scale continuous alcohol-free beer production. Czech Journal of Food Sciences, 27, 267-275.

Lehnert, R., Kuřec, M., Brányik, T., \& Teixeira, J. A. (2008). Effect of oxygen supply on flavor formation during continuous alcohol-free beer production: a model study. Journal of the American Society of Brewing Chemists, 66, 233-238. https://doi.org/10.1094/ASBCJ2008-0910-01.

Lehnert, R., Novák, P., Macieira, F., Kuřec, M., Teixeira, J. A., \& Brányik, T. (2009). Optimisation of lab-scale continuous alcoholfree beer production. Czech Journal of Food Sciences, 27, 267-275.

Li, H.-J., \& Deinzer, M. L. (2009). 32 - Proanthocyanidins in Hops A2Preedy. In R. Victor (Ed.), Beer in health and disease prevention (pp. 333-348). San Diego: Academic Press. https://doi.org/10.1016/ B978-0-12-373891-2.00032-8.

Liguori, L., De Francesco, G., Russo, P., Perretti, G., Albanese, D., \& Di Matteo, M. (2015). Production and characterization of alcohol-free beer by membrane process. Food and Bioproducts Processing, 94, 158-168. https://doi.org/10.1016/j.fbp.2015.03.003.

Long, T.E., Bagrodia, S., Moreau, A., Duccase, V. (2000). Process for improving the flavor retaining property of polyester/polyamide blend containers for ozonated water. United States patent No. US6042908 A. Eastman Chemical Company

Lu, Y., Williamson, B., \& Gillespie, R. (2009). Recent advancement in application of hydrophobic interaction chromatography for aggregate removal in industrial purification process. Current Pharmaceutical Biotechnology, 10(4), 427-433.

Lucas, S., Cocero, M. J., Zetzl, C., \& Brunner, G. (2004). Adsorption isotherms for ethylacetate and furfural on activated carbon from supercritical carbon dioxide. Fluid Phase Equilibria, 219, 171179. https://doi.org/10.1016/j.fluid.2004.01.034.

Maier, H. G. (1973). On the sorption of volatile aroma constituents by foods-VII. Aliphatic aldehydes. Zeitschrift für LebensmittelUntersuchung und -Forschung, 151(6), 384-386. https://doi.org/ 10.1007/BF01464887.

Maier, H. G., \& Hartmann, R. U. (1977). The adsorption of volatile aroma constituents by foods - VIII. Adsorption of volatile carbonyl compounds by amino acids. Zeitschrift für Lebensmittel-Untersuchung und -Forschung, 163(4), 251-254. https://doi.org/10.1007/ BF02425353.

Makin, E.C. (1984). Purification of vanillin. United States patent No. US4474994 A
Mameniskis, W., Washall, T. (1974). Purification of a material containing aldehyde impurities. United States patent No. US3816478 A. Atlantic Richfield Co,

McGuinness, J. D., Laws, D. R. J., Eastmond, R., \& Gardner, R. J. (1975). The estimation and significance of catechin and dimeric catechin in beer. Journal of the Institute of Brewing, 81, 237-241. https://doi.org/10.1002/j.2050-0416.1975.tb03684.x.

McNeely, G.W., Woodward, A.J. (1993). Modified polyethylene terephthalate. United States patent No. US5250333 A. Hoechst Celanese Corporation

Medeiros, A. B. P., Pandey, A., Vandenberghe, L. P. S., Pastore, G. M., \& Soccol, C. R. (2006). Production and recovery of aroma compounds produced by solid-state fermentation using different adsorbents. Food Technology and Biotechnology, 44, 47-51.

Medina, I., \& Martínez, J. L. (1997). Dealcoholisation of cider by supercritical extraction with carbon dioxide. Journal of Chemical Technology and Biotechnology, 68, 14-18. https://doi.org/10.1002/ (SICI)1097-4660(199701)68:1<14::AID-JCTB589>3.0.CO;2-E.

Mehra, R. K., \& Pandya, K. C. (1938). The condensation of aldehydes with amides-Part II. The condensation of cinnamaldehyde. Proceedings of the Indian Academy of Sciences - Section A, 7(6), 376-380. https://doi.org/10.1007/BF03045405.

Meilgaard, M. C. (1975). Flavor chemistry in beer: Part II: Flavor and flavor threshold of 239 aroma volatiles. Master Brewers Association of the Americas, 12, 151-168.

Montanari, L., Marconi, O., Mayer, H., \& Fantozzi, P. (2009). Chapter 6-production of alcohol-free beer. In V. R. Preedy (Ed.), Beer in health and disease prevention (pp. 61-75). San Diego: Academic Press. https://doi.org/10.1016/B978-0-12-373891-2. 00006-7.

Monteiro, O. A. C., \& Airoldi, C. (1999). Some studies of crosslinking chitosan-glutaraldehyde interaction in a homogeneous system. International Journal of Biological Macromolecules, 26(2-3), 119-128. https://doi.org/10.1016/S0141-8130(99)00068-9.

Montgomery, M. W., \& Day, E. A. (1965). Aldehyde-amine condensation reaction: a possible fate of carbonyls in foods. Journal of Food Science, 30, 828-832. https://doi.org/10.1111/j.1365-2621.1965. tb01849.x.

Müller, M., Bellut, K., Tippmann, J., \& Becker, T. (2016). Physical methods for dealcoholization of beverage matrices and their impact on quality attributes. Chemie-Ingenieur-Technik, 88, 1911-1928. https://doi.org/10.1002/cite.201600071.

Müller-Maatsch, J., Gurtner, K., Carle, R., \& Björn Steingass, C. (2019). Investigation into the removal of glucosinolates and volatiles from anthocyanin-rich extracts of red cabbage. Food Chemistry, 278, 406-414. https://doi.org/10.1016/j.foodchem.2018.10.126.

Murakami, A., Kawasaki, Y., Ohta, R., \& Furukawa, J. (2013). Malt beverage having reduced wort off-flavor and process for production thereof. In United States patent.

Narziss, L., Back, W., \& Leibhard, M. (1991). Optimization of biological processes for the production of alcohol-free beer using suitable cultures. Brauwelt International, 1, 52-57.

Narziss, L., Back, W., \& Stich, S. (1993). Alcohol removal from beer by countercurrent distillation in combination with rectification (written in German). Bierwelt, 133, 1806-1820.

Nederlandse-Brouwers (2019), Bierconsumptiecijfers 2018 retrieved from https://www.nederlandsebrouwers.nl/biersector/publicaties/ kerncijfers-nederlandse-brouwers/

Neuman, R. C. (2013). Chapter 16: Addition and Substitution Reactions of Carbonyl Compounds. In Organic Chemistry Retrieved from https://chem.ucr.edu/curricularmaterials/neumantectbook.html.

Nilvebrant, N.-O., Reimann, A., Larsson, S., \& Jönsson, L. J. (2001). Detoxification of lignocellulose hydrolysates with ion-exchange resins. Applied Biochemistry and Biotechnology, 91, 35-49. https://doi.org/10.1385/abab:91-93:1-9:35. 
Nomura, A., \& Jones, C. W. (2013). Amine-functionalized porous silicas as adsorbents for aldehyde abatement. ACS Applied Materials \& Interfaces, 5(12), 5569-5577. https://doi.org/10.1021/am400810s.

Normand, V., Avison, S., \& Parker, A. (2004). Modeling the kinetics of flavour release during drinking. Chemical Senses, 29(3), 235-245.

Noyes, W. A., \& Forman, D. B. (1933). Aldehyde-amide condensation. I. Reactions between aldehydes and acetamide. Journal of the American Chemical Society, 55, 3493-3494.

Olya, M. E., \& Pirkarami, A. (2013). Electrocoagulation for the removal of phenol and aldehyde contaminants from resin effluent. Water Science and Technology, 68(9), 1940-1949. https://doi.org/10. 2166/wst.2013.439.

Ottens, M., Saffarionpour, S., Noordman, T.R. (2016). Method of producing beer having a tailored flavour profile (EP14183788.0).

Pandya, K. C., \& Sodhi, T. S. (1938). The condensation of aldehydes with amides-Part I. The condensation of salicylaldehyde. Proceedings of the Indian Academy of Sciences-Section A, 7, 361-368. https:// doi.org/10.1007/BF03045403.

Pereira, V., Albuquerque, F. M., Ferreira, A. C., Cacho, J., \& Marques, J. C. (2011). Evolution of 5-hydroxymethylfurfural (HMF) and furfural (F) in fortified wines submitted to overheating conditions. Food Research International, 44, 71-76. https://doi.org/10.1016/j. foodres.2010.11.011.

Perpète, P., \& Collin, S. (1999a). Contribution of 3methylthiopropionaldehyde to the worty flavor of alcohol-free beers. Journal of Agricultural and Food Chemistry, 47(6), 2374 2378. https://doi.org/10.1021/jf9811323.

Perpète, P., \& Collin, S. (1999b). Fate of the worty flavours in a cold contact fermentation. Food Chemistry, 66, 359-363. https://doi.org/ 10.1016/S0308-8146(99)00085-0.

Perpète, P., \& Collin, S. (2000a). Evidence of Strecker aldehyde excretion by yeast in cold contact fermentations. Journal of Agricultural and Food Chemistry, 48(6), 2384-2386. https://doi.org/10.1021/ jf000071h.

Perpète, P., \& Collin, S. (2000b). How to improve the enzymatic worty flavour reduction in a cold contact fermentation. Food Chemistry, 70, 457-462. https://doi.org/10.1016/S0308-8146(00)00111-4.

Perpète, P., \& Collin, S. (2000c). Influence of beer ethanol content on the wort flavour perception. Food Chemistry, 71, 379-385. https://doi. org/10.1016/S0308-8146(00)00179-5.

Philippe, E., Seuvre, A.-M., Colas, B., Langendorff, V., Schippa, C., \& Voilley, A. (2003). Behavior of flavor compounds in model food systems: a thermodynamic study. Journal of Agricultural and Food Chemistry, 51(5), 1393-1398. https://doi.org/10.1021/ jf020862e.

Raisi, A., \& Aroujalian, A. (2011). Aroma compound recovery by hydrophobic pervaporation: the effect of membrane thickness and coupling phenomena. Separation and Purification Technology, 82, 5362. https://doi.org/10.1016/j.seppur.2011.08.018.

Randall, D.I. (1965). Removal of aldehydes from ethylene oxide. United States patent No. US3213113 A.

Rass, H. A., Essayem, N., \& Besson, M. (2013). Selective aqueous phase oxidation of 5-hydroxymethylfurfural to 2,5-furandicarboxylic acid over $\mathrm{Pt} / \mathrm{C}$ catalysts: influence of the base and effect of bismuth promotion. Green Chemistry, 15, 2240-2251. https://doi.org/10. 1039/c3gc40727f.

Rizzi, G. P. (2008). The Strecker degradation of amino acids: newer avenues for flavor formation. Food Reviews International, 24, 416-435. https://doi.org/10.1080/87559120802306058.

Roh, H. S., Park, J. Y., Park, S. Y., \& Chun, B. S. (2006). Isolation of offflavors and odors from tuna fish oil using supercritical carbon dioxide. Biotechnology and Bioprocess Engineering, 11, 496-502. https://doi.org/10.1007/BF02932073.

Rojas, E. E. G., dos Reis Coimbra, J. S., Minim, L. A., Saraiva, S. H., \& da Silva, C. A. S. (2006). Hydrophobic interaction adsorption of hen egg white proteins albumin, conalbumin, and lysozyme. Journal of
Chromatography B: Analytical Technologies in the Biomedical and Life Sciences, 840(2), 85-93. https://doi.org/10.1016/j.jchromb. 2006.04.033.

Russo, P., Liguori, L., Albanese, D., Crescitelli, A., \& Di Matteo, M. (2013). Investigation of osmotic distillation technique for beer dealcoholization. Chemical Engineering transactions, 32, 17351740. https://doi.org/10.3303/CET1332290.

Saadati, F., Khani, N., Rahmani, M., \& Piri, F. (2016). Preparation and characterization of nanosized copper (II) oxide embedded in hypercross-linked polystyrene: highly efficient catalyst for aqueous-phase oxidation of aldehydes to carboxylic acids. Catalysis Communications, 79, 26-30. https://doi.org/10.1016/j.catcom. 2015.12.016

Sae-Ung, S., \& Boonamnuayvitaya, V. (2008). Direct synthesis and characterization of amine-functionalized mesoporous silica materials and their applications as formaldehyde adsorbents. Environmental Engineering Science, 25, 1477-1485. https://doi.org/10.1089/ees. 2007.0237.

Saffarionpour, S., \& Ottens, M. (2018). Recent advances in techniques for flavor recovery in liquid food processing food. Engineering Reviews, 10(2), 81-94. https://doi.org/10.1007/s12393-017-9172-8.

Saffarionpour, S., Sevillano, D. M., Van der Wielen, L. A. M., Noordman, T. R., Brouwer, E., \& Ottens, M. (2016). Selective adsorption of flavor-active components on hydrophobic resins. Journal of Chromatography A, 1476, 25-34. https://doi.org/10.1016/j. chroma.2016.10.053.

Sahu, A. K., Srivastava, V. C., Mall, I. D., \& Lataye, D. H. (2008). Adsorption of furfural from aqueous solution onto activated carbon: kinetic, equilibrium and thermodynamic study. Separation Science and Technology, 43, 1239-1259. https://doi.org/10.1080/ 01496390701885711.

Saison, D., De Schutter, D. P., Uyttenhove, B., Delvaux, F., \& Delvaux, F. R. (2009). Contribution of staling compounds to the aged flavour of lager beer by studying their flavour thresholds. Food Chemistry, 114, 1206-1215. https://doi.org/10.1016/j.foodchem.2008.10.078.

Saltmarch, M., \& Labuza, T. P. (1982). Nonenzymatic browning via the Maillard reaction in foods. Diabetes, 31, 29-36.

Santos, J., Dariva, R., Mossi, A., Stuart, G., \& Nascimento, I. (2007). Preliminary study of the influence of $\mathrm{CO} 2$ extraction conditions on the ester, aldehyde, ketone and hydrocarbon content of grape bagasses from jam production. Brazilian Journal of Chemical Engineering, 24, 637-642.

Schneider-Bernlöhr, H., Fiedler, H., Gerber, M., Weber, C., \& Zeppezauer, M. (1981). Alcohol dehydrogenase from leuconostoc mesenteroides: molecular properties in comparison with the yeast and horse liver enzyme. International Journal of Biochemistry, 13(12), 1215-1224. https://doi.org/10.1016/0020-711X(81)900677

Schonberg, A., \& Moubacher, R. (1952). The Strecker degradation of amino acids. Chemical Reviews, 50, 261-277. https://doi.org/10. 1021/cr60156a002.

Schroeder, M.A.F., Fifer, R.A., Morris, J.B. (1995). The relationship of chemical structure to supercritical-fluid solubility and cosolventmodifier properties: a literature review.

Selecký, R., Šmogrovičová, D., \& Sulo, P. (2008). Beer with reduced ethanol content produced using Saccharomyces cerevisiae yeasts deficient in various tricarboxylic acid cycle enzymes. Journal of the Institute of Brewing, 114, 97-101.

She, M., \& Hwang, S.-T. (2006). Recovery of key components from real flavor concentrates by pervaporation. Journal of Membrane Science, 279, 86-93. https://doi.org/10.1016/j.memsci.2005.11.034.

Shimizu C, Takashio M (2003) Process for producing malt alcoholic drink. (WO2002004593A1) retrieved from https://patents.google. com/patent/WO2002004593A1/en

Sieben, R.L., Zastrow, K.D. (1991). Step mashing process for producing low alcohol beer. United States patent No. US5021246 A 
Smit, B. A., Engels, W. J. M., \& Smit, G. (2009). Branched chain aldehydes: production and breakdown pathways and relevance for flavour in foods. Applied Microbiology and Biotechnology, 81(6), 987-999. https://doi.org/10.1007/s00253-008-1758-x.

Smith, M. B., \& March, J. (2006a). Addition to Carbon-Hetero Multiple Bonds (pp. 1251-1476). March's Advanced Organic Chemistry. https://doi.org/10.1002/9780470084960.ch16.

Smith, M. B., \& March, J. (2006b). Oxidations and Reductions (pp. 1703-1869). March's Advanced Organic Chemistry. https://doi. org/10.1002/9780470084960.ch19.

Sohrabvandi, S., Mousavi, S. M., Razavi, S. H., Mortazavian, A. M., \& Rezaei, K. (2010). Alcohol-free beer: Methods of production, sensorial defects, and healthful effects. Food Reviews International, 26, 335-352. https://doi.org/10.1080/87559129.2010.496022.

Speer DV, Morgan CR, Blinka TA, Cotterman RL (1999) By-product absorbers for oxygen scavenging systems. United States patent No. US5942297 A

Strejc, J., Siříšt’ová, L., Karabín, M., Almeida e Silva, J. B., \& Brányik, T. (2013). Production of alcohol-free beer with elevated amounts of flavouring compounds using lager yeast mutants. Journal of the Institute of Brewing, 119, 149-155. https://doi.org/10.1002/jib.72.

Strommen, M., \& Gesser, H. D. (2011). The trapping of indoor air contaminants. Central European Journal of Chemistry, 9, 404-409.

Suloff, E. C. (2002). Sorption behaviour of an aliphatic series of aldehydes in the presence of poly(ethylene terephthalate) blends containing aldehyde scavenging agents. Blacksburg: Virginia Polytech Institute and State University.

Takura T, Ota T, Owa Y (2012). Unfermented beer-flavored malt beverage having reduced unpleasant wort flavor and method for producing the same (US20120207909A1), retrieved from http://www. freepatentsonline.com/y2012/0207909.html

Tejedor, D., \& Garcia-Tellado, F. (2007). Chemo-differentiating ABB multicomponent reactions. Privileged building blocks. Chemical Society Reviews, 36(3), 484-491. https://doi.org/10.1039/b608164a.

Temiño, D. M. R. D., Hartmeier, W., \& Ansorge-Schumacher, M. B. (2005). Entrapment of the alcohol dehydrogenase from Lactobacillus kefir in polyvinyl alcohol for the synthesis of chiral hydrophobic alcohols in organic solvents. Enzyme and Microbial Technology, 36, 3-9. https://doi.org/10.1016/j.enzmictec.2004.01. 013.

Tojo, G., Fernández, M. (2007) Permanganate. In: Oxidation of Primary Alcohols to Carboxylic Acids: A Guide to Current Common Practice. Chapter 1, 1-12. https://doi.org/10.1007/0-387-35432-8_1

van Iersel, M. F. M., Meersman, E., Swinkels, W., Abee, T., \& Rombouts, F. M. (1995). Continuous production of non-alcohol beer by immobilized yeast at low temperature. Journal of Industrial Microbiology, 14(6), 495-501. https://doi.org/10.1007/ BF01573964.

Van Iersel, M. F. M., Brouwer-Post, E., Rombouts, F. M., \& Abee, T. (2000). Influence of yeast immobilization on fermentation and aldehyde reduction during the production of alcohol-free beer. Enzyme and Microbial Technology, 26(8), 602-607. https://doi.org/10.1016/ S0141-0229(00)00140-X.

Vanderhaegen, B., Neven, H., Verachtert, H., \& Derdelinckx, G. (2006). The chemistry of beer aging - a critical review. Food Chemistry, 95, 357-381. https://doi.org/10.1016/j.foodchem.2005.01.006.

Velíšek, J. (2014). The chemistry of food. Oxford: Wiley Blackwell.

Vidal, L., Parshintsev, J., Hartonen, K., Canals, A., \& Riekkola, M. L. (2012). Ionic liquid-functionalized silica for selective solid-phase extraction of organic acids, amines and aldehydes. Journal of Chromatography A, 1226, 2-10. https://doi.org/10.1016/j.chroma. 2011.08.075.

Weil, J. R., Dien, B., Bothast, R., Hendrickson, R., Mosier, N. S., \& Ladisch, M. R. (2002). Removal of fermentation inhibitors formed during pretreatment of biomass by polymeric adsorbents. Industrial and Engineering Chemistry Research, 41, 6132-6138.

Welch, C. J., Biba, M., Drahus, A., Conlon, D. A., Tung, H. H., \& Collins, P. (2003). Selective removal of a pharmaceutical process impurity using a reactive resin. Journal of Liquid Chromatography and Related Technologies, 26, 1959-1968. https://doi.org/10.1081/ JLC-120021763.

Weschenfelder, T. A., Lantin, P., Viegas, M. C., de Castilhos, F., \& Scheer, A. P. (2015). Concentration of aroma compounds from an industrial solution of soluble coffee by pervaporation process. Journal of Food Engineering, 159, 57-65. https://doi.org/10.1016/ j.jfoodeng.2015.03.018.

Wiegner, J. P., Voerckel, V., Nagel, M., Eckert, R., Sela, M., \& Munjal, S. (2001). Extruded products from polyethylene terephthalate with reduced acetaldehyde content and process of their production (WO2001000724 A1). Midland: The Dow Chemical Company.

Yahya, H., Linforth, R. S. T., \& Cook, D. J. (2014). Flavour generation during commercial barley and malt roasting operations: a time course study. Food Chemistry, 145, 378-387. https://doi.org/10. 1016/j.foodchem.2013.08.046.

Yamashita, K., Noguchi, M., Mizukoshi, A., \& Yanagisawa, Y. (2010). Acetaldehyde removal from indoor air through chemical absorption using L-cysteine. International Journal of Environmental Research and Public Health, 7(9), 3489-3498. https://doi.org/10.3390/ ijerph7093489.

Yano, M., Back, W., \& Krottenthaler, M. (2008). The impact of low heat load and activated carbon treatment of second wort on beer taste and flavour stability. Journal of the Institute of Brewing, 114, 357-364. https://doi.org/10.1002/j.2050-0416.2008.tb00780.x.

Yaylayan, V. A. (2003). Recent advances in the chemistry of Strecker degradation and Amadori rearrangement: implications to aroma and color formation. Food Science and Technology Research, 9, 1-6. https://doi.org/10.3136/fstr.9.1.

Zhang, Y., Luo, J., Bi, J., Wang, J., Sun, L., Liu, Y., Zhang, G., Ma, G., \& $\mathrm{Su}, \mathrm{Z}$. (2010). Efficient separation of homologous $\alpha$-lactalbumin from transgenic bovine milk using optimized hydrophobic interaction chromatography. Journal of Chromatography A, 1217(23), 3668-3673. https://doi.org/10.1016/j.chroma.2010.03.060.

Zhu, M., Ruijter, E., \& Wessjohann, L. A. (2004). New scavenger resin for the reversible linking and monoprotection of functionalized aromatic aldehydes. Organic Letters, 6, 3921-3924. https://doi.org/10. 1021/ol048610h.

Zhu, P., Chen, X., Roberts, C.G. (2006) Method of use for aldehyde removal (US7041220 B2) retrieved from https://patents.google. com/patent/US7041220B2/en

Zhu, Y., Li, H., Zheng, Q., Xu, J., \& Li, X. (2012). Amine-functionalized SBA-15 with uniform morphology and well-defined mesostructure for highly sensitive chemosensors to detect formaldehyde vapor. Langmuir, 28(20), 7843-7850. https://doi.org/10.1021/la300560j.

Publisher's Note Springer Nature remains neutral with regard to jurisdictional claims in published maps and institutional affiliations. 